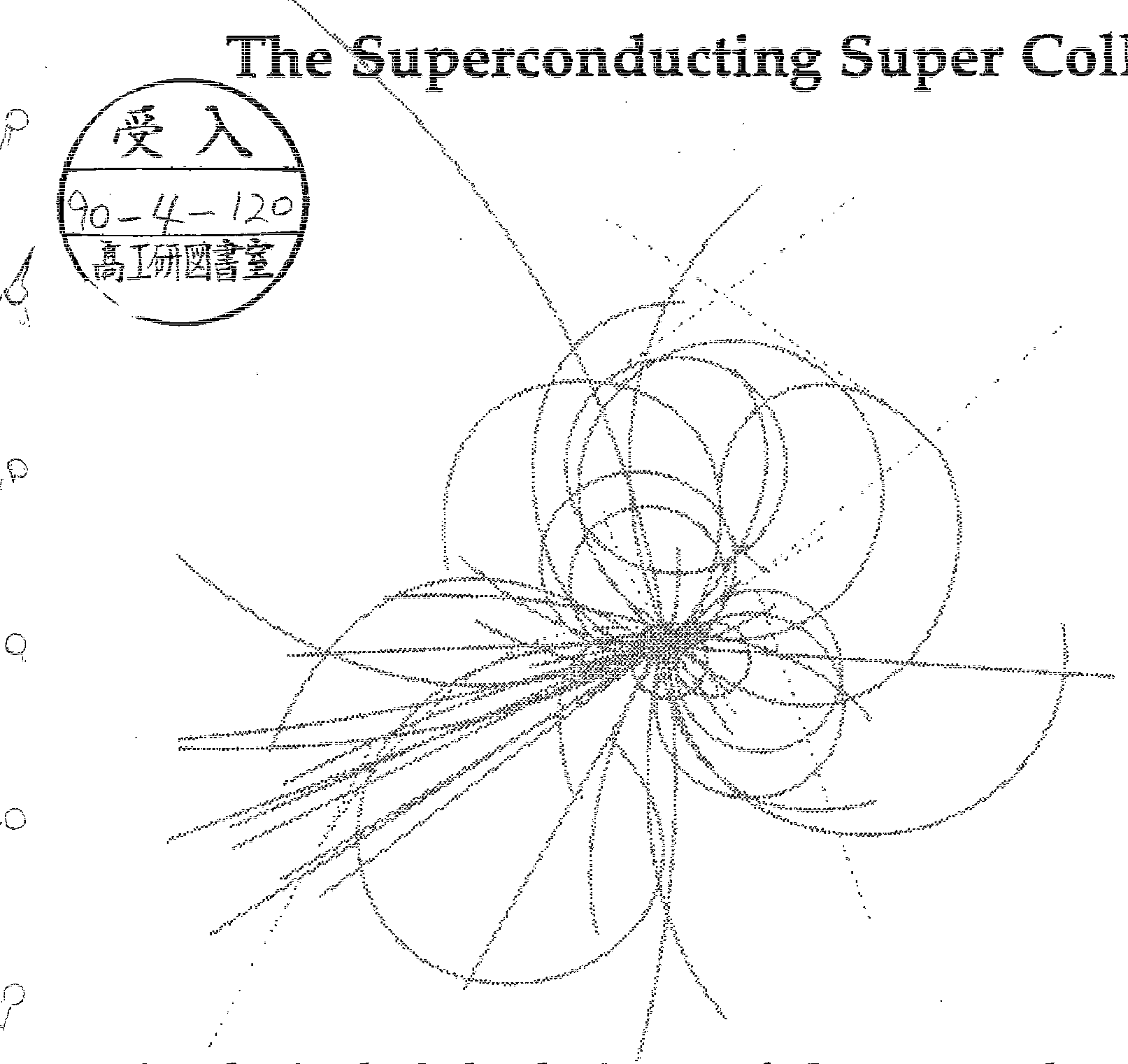

Analytical Calculations of Smear and Tune Shift

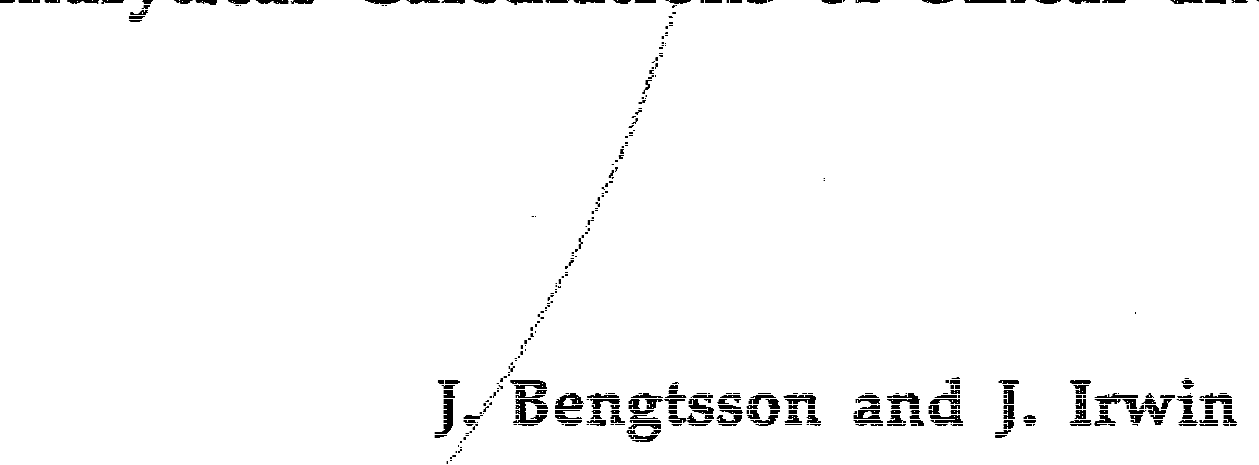

\author{
SSC Laboratory
}

February 1990 
Analytical Calculations of Smear and Tune Shift

\author{
J. BHNGTSSON* AND J. IRWIN \\ Superconducting Super Collider Laboratory \\ Dallas; $\mathrm{TX} 73237$
}

February 1990

"Present address: Lawrence Berkeley Laboratory, One Cyclotron Road, Berkeley, CA 94720 .

$\dagger$ Present address: Stanford Linear Accelerator Center, P.O. Box 4349 , Stanford, CA 94309.

Operated by Universities Research Association, Inc, for the U.S. Department of Energy under Contract No. DE-AC02-89ERA0486. 


\title{
Analytical Calculations of Smear and Tune Shift
}

\author{
J. BENGTSSON* AND J. IRWIN $\dagger$ \\ Superconducting Super Collder Laboratory $\frac{\frac{1}{t}}{4}$ \\ Dallas, TX 75237 \\ February 1990
}

\begin{abstract}
We have applied and generalized the Lie algebraic formalism developed by E. Forest to calculate smear and tune shifts due to random and systematic multipole errors for the SSC. In particular, we have calculated smear to the first order in the multipole strength, and tune shifts to the second order. Systematic errors up to octupoles, random errors up to decapoles, and feed-down effects due to closed orbit distortions have been included. For random errors the spread of the smear for an ensemble of accelerators has also been calculated.

The analytical results have been compared with extensive tracking results (averages over 100 seeds have been used for random errors). A histogram of the smear is presented. By Fourier analyzing the tracking results, we have been able to isolate and compare contributions to the smear from different multipoles.

Calculations have been done to study the performance of candidates for the SSO lattice with 4 , 5 or 6 dipoles per hal cell, 1 or $2 \mathrm{TeV}$ injection energy; and 4 or $5 \mathrm{~cm}$ magnet aperture. The improventent obtained by correcting the systematic multipole errors have also been included.
\end{abstract}

* Present address: Lawrence Berkeley Laboratory, One Cyclotron Road, Berkeley, CA 94720.

$\dagger$ Present address: Stanford Linear Accelerator Center, P.O. Bor 4349, Stanford, CA 94309.

Operated by Universities Research Association, Inc, for the U.S. Department of Energy under Contract No. DE-AC02-89ER40486. 


\section{Contents}

1. Introduction . . . . . . . . . . . . . = 1

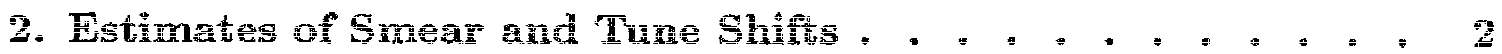

2.1 The Definition of Smear . . . . . . . . . . . . . . 2

2.2 Sources of Smear and Tune Shifts . . . . . . . . . . . . 3

2.3 Estimates of Smear and Tune Shifts . . . . . . . . . . . 5

3. Smear and Tune Shift from Lie Generators . . . . . . 13

3.1 The Exponential Lie Operator . . . . . . . . . . . 13

3.2 The Algebra of Exponential Lie Operators . . . . . . . . . 14

3.3 Lie Product Representations of Accelerator Lattices . . = . = 16

3.4 Lie Product Normal Form . . . . . . . . . . . . . . . . 18

3.5 Lie Algebraic Expression for Tune Shift and Smear . . . . . . . . 20

3.6 Second Order The Shifts . . . . . . . . . . . . 21

4. Analytical Expressions for Smear and Tune Shifts . . . 24

4.1 Smear to First Order in the Multipole Strength . . . . . . . 25

4.2 Tune Shifts to First Order in the Multipole Strength . . . . . 26

4.3 Second Order Tune Shifts . . . . . . . . . . . . 27

5. Closed Orbit Perturbations . . . . . . . . . . . 29

5.1 Calculation of the Closed Orbit Distortions . . . . . . . . 29

5.2 Calculation of the Feed-down . . . . . . . . . . . 32

6. Chromatic Perturbations . . . . , . , , . = = , = 33

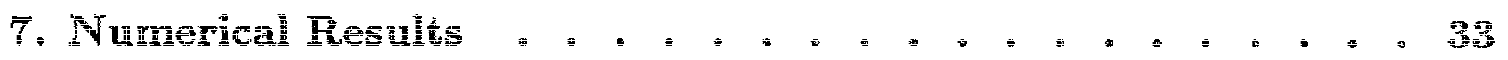

7.1 Tune Shifts and Smear . . . . . . . . . . . 35

7.2 Smear versus Tune . . . . . . . . . . . . . = = 42

8. Comparison with Tracking . . . . . . . . . . . . 46

8.1 Fourier Analysis of Tracking Results . . . . . . . . . . . . . 46

8.2 Smear due to Random Multipoles . . . . . . . . . . 49

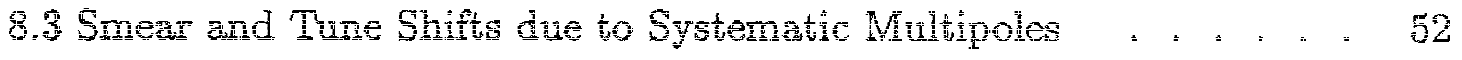

8.4 Closed Orbit Distortions . . . . . . . . . 54

9. Summary and Condusions , , , . . . , , , , 56 
Ackmowledgments . . . . . . . . . . . . . . . . . . . .

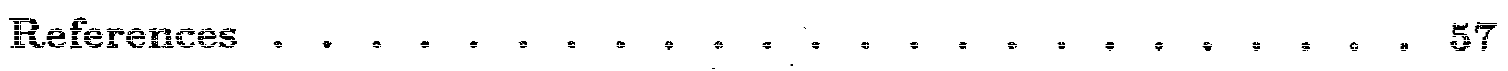




\section{Introduction}

Early in the design process for the $S S \mathrm{C}$, the concepts of tune shift and smear were chosen as first order meastres of merit of machine designs. Smear was to be a measure of departure from linearity. It has been used extensively by the SSC Central Design Group recently in comparing various systematic multipole error correction schemes.[1,2] The intention of the concept is clear. Unfortunately, several different quantitative definitions of this term have appeared in the literature. Recently, Furman and Peggs [B] addressed this problem and have suggested a convention for the use of this word which we will follow in this paper.

E. Forest [i] pointed out that tune hifts and smear could be easily calculated from generators that appear in the lie algebraic analysis of one-turn maps. Other analytical methods have been reported. [5, 6$]$ In this paper, we follow the approach of $\mathrm{E}$. Forest and extend his results in the following ways:

i) We include randon decapole errors in the dipole magnets and show that indeed their contribution to the smear is negligible.

ii) We derive analytical expressions for the spread of the smear for an ensemble of machines with specified mo magnet errors.

wiin) We derive expressions for the smear in the presence of closed orbit distortions (from dipole field errors, quadrupole misalignment, and beam position monitor (bpm) displacement errors).

iv) We compare our numerical results for the average smear and the spread of the smear with extensive tracking results, using values obtained from 100 different randon seeds in the case of random multipoles for the SSC lattice. We are, therefore, also able to present a histogram of the smear.

v) We are able, by Fonrier analysis of the tracking data, to isolate and compare contributiong to the smear from different multipoles.

vi) We anialyze and compute the first and the second order contributions of systematic sextupoles and octupoles to tune shifts. 
As a result of this work we can make the following dains:

i) At important amplitudes, the analytical expressions adequately reproduce in detail the average smear, the spread of the smear, and tune shifts derived from tracking. Thus, one can with confidence use analytical techniques to study a wide variety of operating points and latice configurations. Computation times for each working point are reduced from hours on the CFAY (needed to obtain results with good statistical significance) to seconds on the VAX.

it) The contributions of various multipoles and closed orbit errors and dependence on amplitude, momertum, and woring tune are now clear and the meaning of smear is transpareat.

ini) The spread in smear values is typicaly $40 \%$ of its average value, This fact is significant in assessing the confidence that a specified set of parameters will yield the desired linearity. The need for an addional specification, such as long-tem dynamic aperture (with modulation included) is clear, and one will want to do long-term tracking for a set of seeds for selected working points.

\section{Estmates of Smear and Tune Shifts}

\subsection{THE DEFINTTON OF SMEAR}

We take the point of view that smear is to be a measure of machine nonlinearity. Under circumstances where quadrupole and skew-quadrupole errors are present, or where a non-zero closed ortit results in feed-down to produce quadrupole and shew-quadrupole errors, we analyze the resultant linear latice to obtain linear eigensolutions and describe the motion by reference to their respective eigen-amplitudes and aigen-actions. We then follow the recomendations of Ref. $[3]$ and define the smear $S\left(A_{1}\right)$ and $S\left(A_{2}\right)$ of the eigen-actions $A_{1}$ 
and $A_{2}$. When there is no hnear coupling, we have

$$
S_{x} \equiv \frac{\sqrt{\overline{\Delta A_{x}^{2}}}}{\overline{\hat{A}_{x}}} \approx \frac{\sqrt{\overline{\Delta J_{x}^{2}}}}{2 \bar{J}_{x}}, \quad \text { if } \quad \Delta \bar{J}_{x} \ll \bar{J}_{x}
$$

where $A_{x}$ is the horizontal betatron amplitude and $\bar{A}_{\bar{z}}$ the average. For random errors, we will calculate the averages over añ ensemble of accelerators. For computation, we will use the following average

$$
\left.<\mathfrak{S}_{x}^{\hat{2}}\right\rangle_{\text {seeds }} \equiv \frac{\left\langle\overline{\Delta \sqrt{J_{x}^{2}}}\right\rangle_{\text {seeds }}}{4_{x}^{2}}
$$

and for the $\sigma$

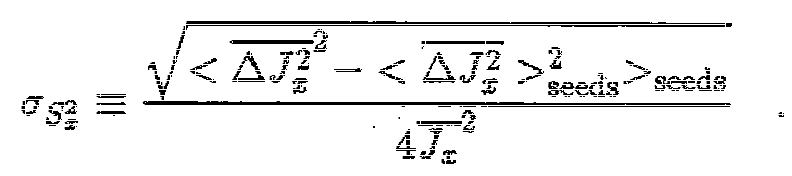

To first order in the mutipoles strengh, $\bar{J}$ may be replaced by $\bar{J}_{x}$. Smilar expression holds for the vertical plane. For comparison reasons, the square root of these quantities will be presented.

\subsection{SOURCES OF SMEAR AND TUNE SHFTS}

With the exception of random errors, we assume that the lattice is a repetition of identical cells. We wish to find the tune shifts and smear from chromaticity sextupoles, errors in dipole magnets, and misalignment errors of the main quadrupoles. Some of these contributions are the sane for each cell, namely from the chromaticty sextupoles, and from the systematic errors in the dipole magnets. Some vary randomly from cell to cell, namely the contribution from the random multipole errors in the dipole magnets, and the misalignment errors. The random misalignment errors of the quadrupoles contribute to a random closed orbit in the dipoles and chromaticity sextupoles, and in this way produce random perturbations. 
Since a tolerable design must have both tiny tune shifts and small smear within the usable aperture, it follows quite simply that the machine may be regarded as basicaly linear, and departures from hinearity may be introduced as perturbations.

For evaluating systematic perturbations it is suficient to limit the analysis to one cell. Clearly, the ture shift of the machine will be equal to the tune shift of one cell times the number of cells. On the ther hand, the smeat of the full machine will be identical to that for one cell. This is clear if one notes that smear measures the departure from linear orbits, and a one-cell machine is indeed the endless iteration of identical cells. The smear measured in the second cell of a two-cll machine must then be identical to that in the first cell, and no difrerent than the smear measured in a onecll machine. To obtain a low smear per cell, one needs to choose a worling point so that the phase advance per cell is not near a resonance. This choice of tune imples that systematic errorg will contribute importantly to tune shifts but little to smear.

On the other hand, for the random errors the full latice has to be studied. If we consider amphtude resonances

$$
n_{\bar{x}} z_{z}+n_{y y} \nu_{y}=p, \quad n_{x}, n_{y}, \tilde{p}=\operatorname{integer} \quad
$$

the statement of the previous paragraph implies that the systematic errors will only excite resonances for which the hamonic $P$ is equal to 0 or the number of cells (due to the symmetry of the lattice). For the random errors, many nore resonarce can contribute to the mear. The tune shifts remain small since the random perturbations of the phase finctuate around gero from cell to cell.

Since the tune shif is an average over many turns of the phase shift per tum, it can be equivalenty regarded as an average over initial phase. It follows that the frot order "odd" multipoles, such as sexupoles and decapoles, cannot contribute to tune shitt. This fortunate circumstance means that the tolerances on the sextupole can be loosened. However, second order perturbations then 
come in to play. Hence, second order contributions to tune shift from sextupoles must be computed. All other perturbations for tune shit and smear can be adequately calculated from first-order perturbation theory.

\subsection{ESTMATES OF SMEAR AND TUNE SHIFTS}

We begin by assuming that the lnear latice has been analyzed, that coupling is negligible, and that the solution to the linear motion is given by the usual Floquet solition [7]

$$
\bar{w}(s)=\sqrt{2 \beta_{x}(s) \overrightarrow{\hat{l}_{2}}} \cos \left[\hat{\theta}_{x}+\phi_{x}(s)\right]
$$

where

$$
\phi_{x}(s) \equiv \int_{0}^{s} \frac{d \tau}{\beta_{x}(\tau)}
$$

$J_{x}$ is the invariant action associated whthe $\bar{x}$-degree of freedom $\left(2 J_{x}\right.$ is the Courant-Snyder invariant), $\theta_{x}$ the initial phase, and $\beta_{x}(s)$ the beta function. It follows that

$$
\tilde{x}^{\prime}=-\sqrt{\frac{2 I_{x}}{\beta_{x}(s)}}\left\{\sin \left[\theta_{x}+\phi_{x}(s)\right]+\alpha_{x}(s) \cos \left[\theta_{x}(s)+\phi_{x}(s)\right]\right\}
$$

where

$$
\alpha_{x}(s) \equiv-\frac{1}{2} \beta_{x}^{\prime}(s)
$$

Then the action and the initial phase are given by the values of $x$ and $x^{\prime}$ through the equations

$$
\begin{aligned}
& \vec{J}_{x}=\frac{1}{2 \beta_{x}}\left\{x^{2}+\left[\beta_{x}(s) x^{3}+\alpha_{x}(s) x^{2}\right]\right. \\
& \theta_{x}=-\arctan \left[\frac{\beta_{x}(s) x^{i}+\alpha_{x}(s) x}{x}\right]-\phi_{x}(s)
\end{aligned}
$$


To first order, the change in action and the change in phase produced by a small change in $x^{i}$ is then given by

$$
\Delta J_{x} \equiv\left[\beta_{x}(s) x^{i}+\alpha_{x}(s) x\right] \Delta x^{i}, \quad \Delta \theta_{x}=-\frac{x}{2 J_{x}} \Delta x^{i}
$$

We note that

$$
\beta_{x}(s) x^{l}+\alpha_{x}(s) x=-\sqrt{2 \beta_{x}(s) \bar{J}_{x}} \sin \left[\theta_{x}+\phi_{t}(s)\right]=\frac{\partial x(s)}{\partial \theta_{x}}, \quad \frac{x(s)}{2 J_{\bar{x}}}=\frac{\partial x(s)}{\partial J_{x}}
$$

so that if the kick $\Delta x^{\prime}$ can be given in terms of the derivative of a potential function through

$$
\Delta x^{\prime}=-\frac{\partial V(x, y)}{\partial x}, \quad \Delta y^{\prime}=-\frac{\partial V(x, y)}{\partial y}
$$

then we can wite Eqs. (2.10) as

$$
\Delta J_{z}=-\frac{\partial V}{\partial \theta_{x}}, \quad \Delta \hat{\theta}_{x}=\frac{\partial V}{\partial J_{x}}
$$

where now $V(x, y)$ is expressed in terms of action-angle variables by writing $x$ and $y$ in tems of action-angle variables. Eqg. (2.13) are reminiscent of Hamilon" equations of motion if interpreted as giving the addional change in and $\theta$ from a perturbing term $V$ in the Hamitonian. $[8,9]$ We will come back to this theme in Chapter 3.

Let us first show that inded there exists such a $V$ for the kicks from magnetic multipoles which we are considening. Indeed, the potential $\bar{V}$ is proportional to the longitudinal component of the magnetic vector potential, $A_{\bar{s}}$. Since when we neglect end effects there are only transverse components to the magnetic field, the fields may then be expressed as the derivative of $A g$ From $\bar{B}=\bar{\nabla} \times \mathbf{A}$, we 
have

$$
\bar{B}_{x}=\frac{\partial \hat{A}_{s}}{\partial y}, \quad \bar{B}_{y}=-\frac{\partial A_{s}}{\partial x}
$$

The kick from the magnetic field is given by $\int \bar{F} d \bar{i}$, where $\bar{F}=q \times \times B$. Thus,

$$
\Delta \tilde{x}^{\prime}=\frac{\Delta p_{x}}{p_{0}}=-\frac{q \bar{L} \bar{B}_{y}}{p_{0}} ; \quad \Delta y^{\prime}=\frac{q L B_{x}}{p_{0}}
$$

Hence

$$
\Delta x^{i}=\frac{q \bar{L}}{p_{0}} \frac{\partial A_{s}}{\partial x}, \quad \Delta y^{i}=\frac{q \bar{L}}{p_{0}} \frac{\partial A_{s}}{\partial y}
$$

from which we may deduce that

$$
V(x, y)=-\frac{q \bar{L}}{p_{0}} A s(x, y)
$$

The first order expressions for phase shift and smear can now be easily found. The tune shift is the phase advance (divided by $2 \pi$ ) per turn averaged over many turns. The action variables are approximately constant, so the average over tums can be taken as an average over initial phase angle. Thus,

$$
2 \pi \Delta v_{\bar{z}}=\left\langle\Delta \theta_{y}\right\rangle_{\theta}=<\sum_{\bar{k}} \frac{\partial V_{k}}{\partial J_{x}}>\theta
$$

The sum over indicates the sum over multipoles in the lattice. To find the smear requires a bit more thought. The changes in $f$ that are given by $\mathrm{Eqs}$. (2.13) result in a distortion of the phase space surfaces for the system. Leting $I_{x}(0)$ and $J_{y}(\theta)$ denote the phase space aturace, then Eqs. (2.13) imply

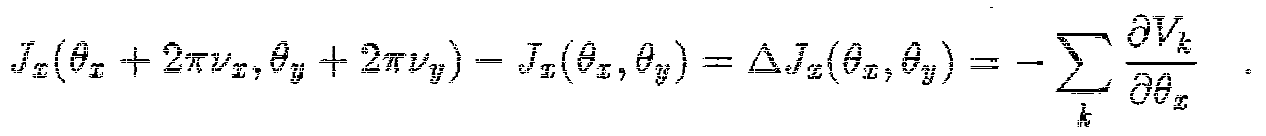

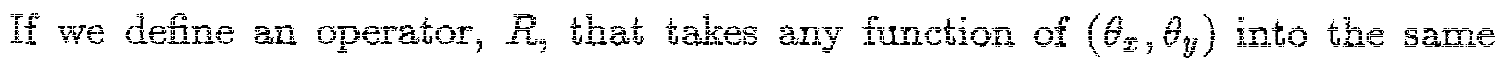
function evaluated at $\left(\hat{\theta}_{x}+2 \pi \nu_{y}, \theta_{y}+2 \pi \nu_{y}\right)$, then Eq. (2.19) may be written

$$
(R-1) J_{\bar{t}}\left(\hat{\theta}_{\bar{w}}, \theta_{\bar{y}}\right)=-\sum_{\frac{l}{k}} \frac{\partial \bar{V}_{k}}{\partial \hat{\theta}_{\underline{x}}}
$$


Formally this may be solved in the form

$$
J_{x}\left(\hat{\theta}_{x}, \hat{\theta}_{y}\right)=\bar{J}_{z}-\frac{1}{R-1} \sum_{k} \frac{\partial V_{k}}{\partial \theta_{z}}
$$

where $1 /(R-1)$ is the inverse operator to $R-1$. Since the $V / b$ are polynomial functions in $x$ and $y_{y}$ and hence in $\cos \theta_{x}, \sin \theta_{x}, \cos \theta_{y}$ and $\sin \theta_{y}$, it follows that $V_{k}$ can be written as a polynomial in exp $\left(\operatorname{tin}_{y} \theta_{x}\right) \exp \left(\operatorname{tin}_{y} \theta_{y}\right) . R-1$ operating on such a term yields a complex number times the original function. Hence, $1 /(R-1)$ is also well defined on such monomials, and by extension, on the polynomial $V_{k}$, assuming no monomials with $n_{g}=n_{y}=0$ occur in the decomposition. The smear is the rme value of $\Delta J_{x}$ divided by two times its average value (Eq. (2.1)), hence,

$$
S\left(\hat{A}_{x}\right)=\frac{1}{2 \bar{J}_{x}}\left[/\left(\frac{1}{R-1} \sum \frac{\partial \bar{V}_{k}}{\partial \theta_{x}}\right)^{2}\right]_{\theta}^{1 / 2}
$$

As an example, we will calculate (to first order) tune shiffs for random normal octupoles and smear for random normal sextupoles. First order tune shift for sextupoles is zero since the $\theta$ average of $x^{n_{x}} y^{n_{y}}$ is zero if $n_{\bar{x}}, n_{y}$, or $n_{\bar{x}}+n_{y}$ is odd. The magnetic multipoles in the SSC dipoles are usially parametrized through the formula[10]

$$
B_{y}+\dot{b} B_{n}=B_{0} \sum_{n=0}^{\infty}\left(b_{n}+i a_{n}\right)(x+i y)^{n},
$$

where $\bar{B}_{0}$ is the design bending field and $b_{n}, a_{n}$ are the normal and skew multipole strengths with the dimension $m^{-n}$. It is customary to quote $a_{n}$ and $b_{n}$ in units of $10^{-4}$ measured at a reference radius $r_{0}=10^{-2} \mathrm{~m}$. If we write

$$
B_{y}+i B_{z}=\widehat{B}_{0} \sum_{n=0}^{\infty}\left(\hat{\theta}_{n}+i \hat{a}_{n}\right)\left(\frac{x+i y}{r_{0}}\right)^{n}, \quad \widehat{B}_{0} \equiv B_{0} \cdot 10^{-4}
$$

then for the SSO these parameters range from 0.1 to 10 . (See Table S-1[11). Given Eq. (2.23) for the magnetic field, it follows that the potential function $V$ 
is given by

$$
V=r_{0} \hat{\theta}_{d} \bar{R} e \sum_{n=0}^{\infty} \frac{1}{n+1}\left(\hat{\bar{\theta}}_{n}+i \hat{a}_{n}\right)\left(\frac{x+\hat{b} v}{r_{0}}\right)^{n+1}
$$

where $\hat{\partial}_{d} \equiv q L B_{0} / p_{0} \cdot 10^{-4}=L / \rho \cdot 10^{-4}$ is $10^{-4}$ times the bend angle of the reference orbit in the dipole magnets, about $2 \pi / 4000 \cdot 10^{-4}$. Hence, the potential for the normal octupole located at $s=s_{\bar{k}}$, is

$$
\bar{V}_{k}^{3 N}=r_{0} \hat{\theta}_{i} \hat{b}_{3 k} \frac{1}{4 r_{0}^{4}}\left(x_{k}^{4}-6 v_{k}^{2} y_{k}^{2}+y_{k}^{4}\right)
$$

A simple way to find the averages over $\theta$ is to write the cosine of $\mathrm{Eq} .(2.5)$ as a sum of complex exponentials, and use the binomial theorem to extract the $\theta$ independent term. For example,

$$
<\cos ^{\frac{4}{4} \theta_{x}}>=\frac{3}{8}, \quad\left\langle\cos ^{2} \theta_{x}>=\frac{1}{2}\right.
$$

so

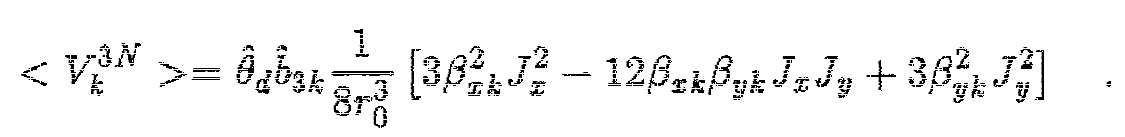

Next we need to sum this quantity over all $k$. For random octupoles, the strength $\hat{b}_{3 k}$ will be $r_{k} \sigma_{\hat{b}_{3}}$, where the $r_{k}$ are normally distributed randon numbers with an rms spread of unity. This, in turn, implies that the sum over $k$ when various randorn seeds are considered, will be

$$
\begin{gathered}
\sum_{k}<V_{k}^{3 N}>=r_{\#} \sqrt{N} \hat{\theta}_{d} \sigma_{\hat{b} 3} \frac{1}{8 r_{0}^{3}}\left[3<\beta_{x k}^{2}>J_{x}^{2}-12<\beta_{x k} \beta_{y k}>J_{z} J_{y}\right. \\
\left.+3<\beta_{y k}^{2}>J_{y}^{2}\right]
\end{gathered}
$$

where $N$ is the total number of dipoles, $r$ is a random number chosen from a nomal distribution of unit width, and the averages of the powers of the beta functions can be taken over any single cell. The derivative of Eq. (2.20) with 
respect to $J_{x}$ or $\bar{J}_{y}$ will give $2 \pi$ times the $z$ and $y$ tune shift, respectively. For example;

$$
2 \pi \Delta v_{x}=\tau_{\#} \sqrt{N} \hat{\theta}_{d} \hat{\sigma}_{b_{x}} \frac{3}{4 r_{0}^{3}}\left[<\beta_{x=}^{\hat{z}}>J_{x}-2<\beta_{x k} \beta_{y k}>J_{y}\right]
$$

To carry this one step further, it is usial to express such a result in terms of the maximum amplitude of oscilation at a point in the ares where the beta function is maximum; namely, we write $\bar{J}_{x}=x_{\text {mEx }}^{2} /\left(2 \beta_{z}^{\max }\right)$ and $\bar{J}_{y}=y_{\max }^{2} /\left(2 \beta_{y}^{\max }\right)$.

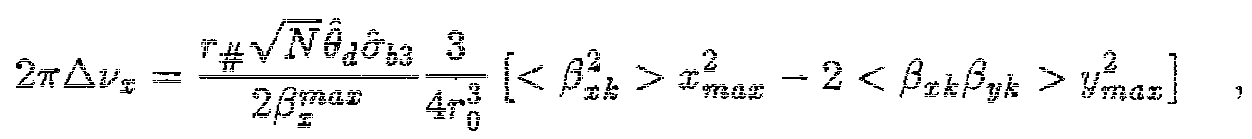

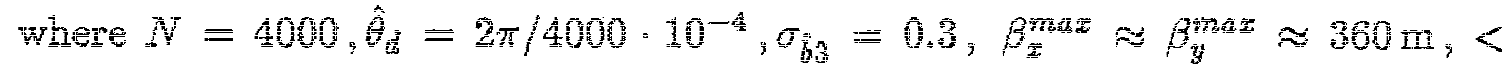
$\left.\beta_{x k}^{2}\right\rangle=4.3 \times 10^{4} \mathrm{~m}^{2}$, and $\left\langle\beta_{* k} \beta_{y k}>=2.8 \times 10^{4} \mathrm{~m}^{2}\right.$. [12] The order of magnitude here is given by the combination of factors:

$$
\begin{aligned}
& \Delta \nu_{t a} \approx \sqrt{N} \frac{\hat{\theta}_{a}}{2 \pi} \sigma_{\hat{b}_{3}} \frac{<\beta_{x}>\frac{\bar{x}^{2}}{r_{0}}}{r_{0}^{2}} \\
& \approx 63 \cdot 10^{-4} \cdot \frac{1}{4000} \cdot 0.3 \cdot 1.2 \cdot 10^{\frac{4}{2}}(0.6)^{2} \approx 0.007
\end{aligned}
$$

More preciselíy

$$
\left(\begin{array}{c}
\Delta v_{x} \\
\Delta v_{y}
\end{array}\right)=F_{\#}\left(\begin{array}{cc}
0.0041 & -0.0052 \\
-0.0052 & 0.0040
\end{array}\right)\left(\begin{array}{c}
w_{m a}^{2} / r_{0}^{2} \\
y_{m \bar{m}}^{2} / r_{0}^{2}
\end{array}\right)
$$

We see here that the first order tune shifts from the random octupoles are normally distributed.

To calculate the smear from sextupoles, we begin with Fi. (2.22). For the nomal sextupole, we have

$$
V_{k}^{2 N}=\hat{\theta}_{i} \hat{b}_{2 k} \frac{1}{3 r_{0}^{2}}\left(x_{k}^{3}-3 x_{k} y_{k}^{2}\right)
$$


Next, we expand $x_{k}, x_{k}^{3}$, and $y_{k}^{2}$ in terms of complex exponentials. For example,

$$
x_{k}^{3}=\left(\frac{\beta_{x h} J_{x}}{2}\right)^{3 / 2}\left[e^{3 i\left(\hat{\theta}_{x}+\hat{\phi}_{x k}\right)}+3 e^{i\left(\hat{\theta}_{x}+\dot{\phi}_{x \xi}\right)}+c c\right],
$$

where $c$ stands for the complex conjugate. The operator $1 /(R-1)$ and the derivative with respect to $y_{x}$ on this term give

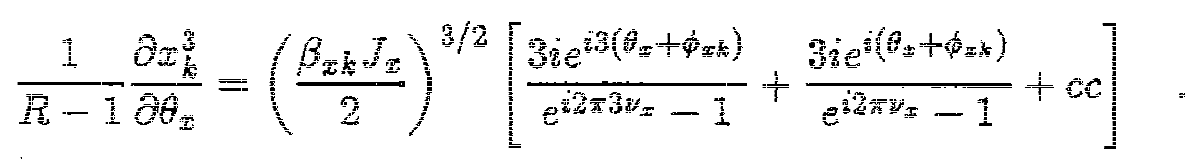

The operations must be performed for $-x_{k} y_{k}^{2}$. Then these are added, summed over $k$, multiplied times itself (summed over $j$ ), averaged over $\theta$, and finaly the square root is taken to get the smear. Instead of proceeding further with this example, we write down a more general expression

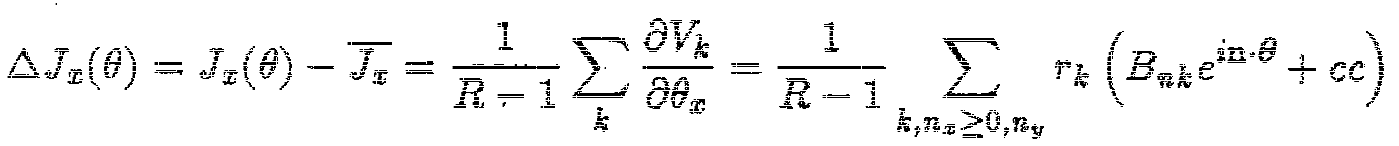

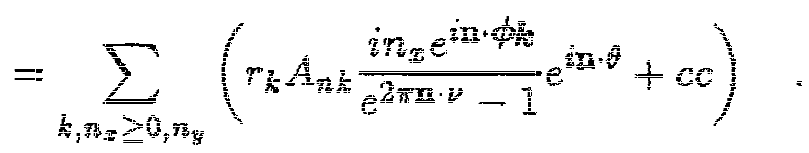

Here, the $i m_{x}$ comes from the derivative with respect to $\theta_{x}$, the denominator is the $R-1$ factor, the $A_{n}$ is real and is a polynomial in the beta functions and the action variables. The sum is restricted to $n_{x} \geq 0$ since the $n_{x}<0$ terms then appear in the complex conjugate (cc) terms.

If we scuare this result and average over $\theta$, we get

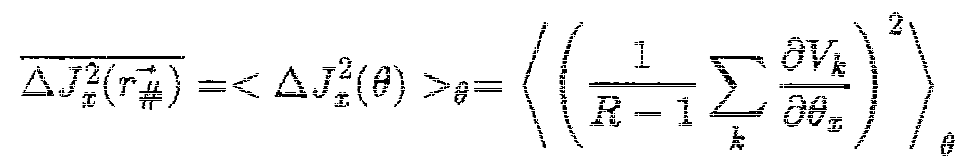

$$
\begin{aligned}
& =\frac{1}{2 \pi} \sum_{j, k, n_{z} \geq 0, n_{y}} r_{j} r_{k}\left[B_{n j} B_{n k}+c c\right] \\
& =\frac{1}{2 \pi} \sum_{j, k_{i} n_{x} \geq 0, n_{y}} r_{j} r_{k} A_{n j} A_{n k} n_{x}^{2} \frac{\cos \mathbf{n} \cdot\left(\phi_{j}-\phi_{k}\right)}{\sin ^{2} \pi n \cdot y} \text {. }
\end{aligned}
$$


Here we see the "resonance denominators" that are important to the smear calculation. If we ask for the average ralue of the above expression, averaged over random seeds, then only the $j=h$ terms survive, and we get

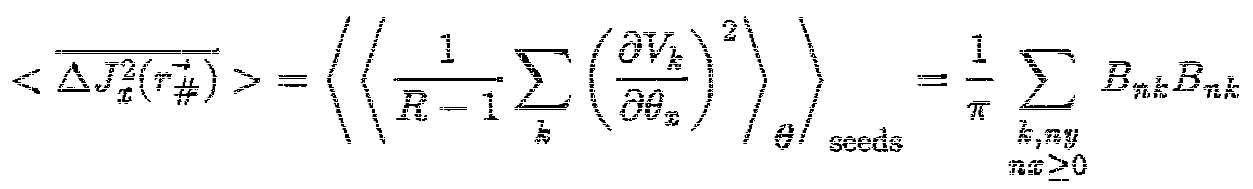

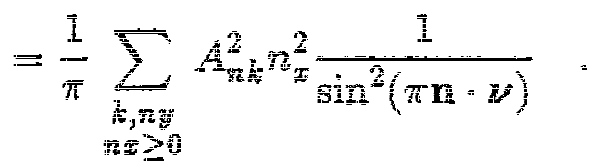

In addition to this average it is of interest to calculate the spread over random seeds of the expression in Eq. $(2.37)$.

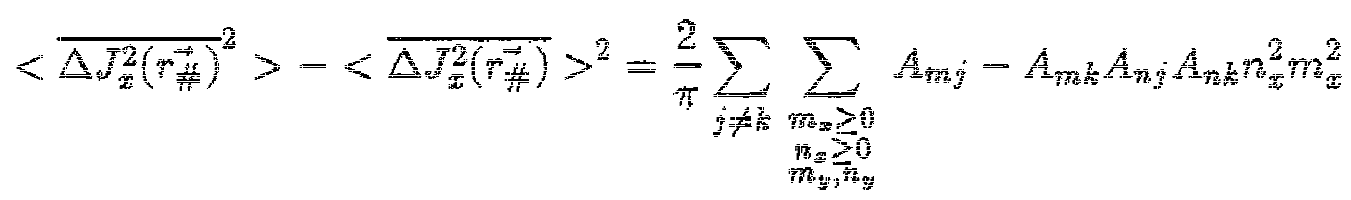

$$
\begin{aligned}
& \frac{\cos m \cdot\left(\phi_{i}-\phi_{i}\right) \cos n \cdot\left(\phi_{j}-\phi_{n}\right)}{\sin ^{2} \pi \mathbf{m} \cdot y \sin ^{2} \pi n \cdot y} \text {. }
\end{aligned}
$$

The precise analytic expressions will be presented in Chapter 4 .

Taking the specifcations in Table $\mathrm{S}-1,[11]$ for nonlinear multipole errors present in the dipoles, the principal contributions typicaly come from the sextupole and the octupole errors. This result depends, of course, on the operating tunes. Higher nultipoles are quite negligible.

Since the total integrated length of the quadrupoles is much smaller than the dipoles, the nonlinearities in the quadrupoles give a negigible contribution to the noninearity of the machine at injection. For collision optics, the nonlinearities from the interaction region giadrupoles can become dominant. Here we limit our attention to the situation at injection.

Random quadrupole and skew-quadrupole errors in the dipoles do not contribute directy to the smear, but they create a sight randomness in the cell-to- 
cell phase advance and beta function. As a result, there is a randon contribution to the nonlinear contributions of the systematic dipole multipoles. This arises also when closed orbit errors are present since they give nomal and skew quadrupole terms through feed-down.

\section{Smear and Tune Shifts from Lie Generators}

In this chapter, we derive expressions for smear and tune shift using Lie algebra techniques. It is possible to extend the above results to higher orders, and as an example, we derive the expression for second order tune shift which we need for sextupoles. Additionally, the Lie algebraic formulation affords insight into the quantities we are computing.

\subsection{ThE ExpoNental LIE OPERATOR}

There have been several descriptions of the Lie algebra techniques. [13, 4, 14, 2$]$ We present here the main results with explanatory comments. The exponential Lie operator is written exp $(: f:)$. It operates on a function space, and is defined by

$$
e^{: \frac{f}{f} g}=g+[f, g]+\frac{1}{2}[f,[f, g]]+\ldots .
$$

where $[f, g]$ is the Poisson bracket of $f$ and $g$. If exp(: $f:$ ) operates on a coordinate function, then the result

$$
\mathfrak{x}_{f}=e^{: f:} x=x+[f, x]+\frac{1}{2}[f ;[f, x]+\ldots
$$

can be interpreted as the value of the coordinate at a time $t=1$, expressed as a function of the coordinates at time $\frac{b}{b}=0$, for a dynamical system with a Hamiltonian $H=-f$. Since the Poisson bracket viewed as an operator falls into 
a class of operators which are derivations (: $f$ : can be viewed as the operator $=d / d t)$, it follows that

$$
e^{i f} x^{n z}=x_{f}^{n h}
$$

and thus for polynomial functions

$$
e^{: f i} g(z)=g\left(e^{: f:} z\right)
$$

Of special interest is the case where $f\left(x, p_{x}, y, p_{y}\right)$ is only anction of $x$ and $y$. Then,

$$
x_{j}=x_{i}, \quad y_{\bar{j}}=y_{i}, \quad p_{x_{i}}=p_{x_{i}}+\frac{\partial f}{\partial x_{i}}, \quad \text { and } \quad p_{y_{f}}=p_{y_{i}}+\frac{\partial f}{\partial y_{i}}
$$

We call this a kick Hamilonian; it can be an accurate representation of a thin magnetic lens. For the mulipole kicks described in Chapter 2, Eq. (2.17),

$$
f\left(x_{i} y\right)=-V(x, y)=\frac{q L}{p_{0}} A_{3}(x, y)
$$

\subsection{THE ALGPBRA OF EXPONENTIAL LIE OPERATORS}

The operator exp(: $\bar{f})$ interpreted as a nap, is necessarily a symplectic map, since it produces a coordmate transformation generated by a Hamiltonian function. Thus these maps may be composed to create an algebra of symplectic maps. Sippose we have two operators

$$
z_{2}=e^{i f_{1}\left(z_{1}\right)} z_{1} ; \quad \text { mapping } z_{1} \text { to } z_{2}
$$

and

$$
z_{3}=e^{f\left(f_{2}\left(z_{2}\right)\right.} z_{2}, \quad \text { mapping } z_{2} \text { to } z_{3}
$$

then the composition

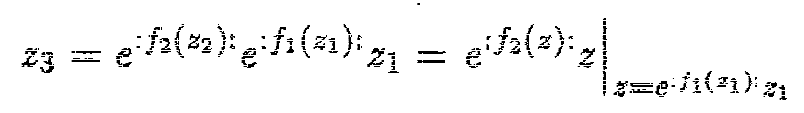

has one exponent expressed in terms of the original variables $z_{1}$, and the second exponent expressed as a function of the internediate variables. A bit of thought 
(and doing one simple example) shows that the result is the same as

$$
z_{3}=e^{i f_{1}\left(z_{1}\right):} e^{: f_{2}\left(z_{1}\right):} z_{1}
$$

Briefy, $f_{2}\left(z_{1}\right)$ operates on $z_{1}$ as if the variable was $z_{2}$, and then because of property from Eq. (3.4) above, the operator exp[: $\left.f_{1}\left(z_{1}\right):\right]$ changes $z_{1}$ everywhere to $z_{2}$ (expressed as a function of $z_{1}$ ). This is exactly the composition desired.

Of course, $\mathrm{Eq}$. (3.10) is more convenient and allows us to build a powerful operator algebra. A combination of particular importance is completely analogous to the similarity transformation so familiar in linear matrix algebra

$$
e^{: g:} e^{: f:} e^{i g:}=e^{: e^{: g ;} f:}=e^{: f\left(e^{: i s} z\right):}
$$

Finaly, there is a theorem, known as the Campbell-Baker-Hausdorf Theorem, by which a product of two operators may be combined into one

$$
e^{f f_{2}} e_{e}^{f f_{3}:}=e^{f t:}
$$

where $f$ is given by

$$
f=f_{2}+f_{1}+\frac{1}{2}\left[f_{2}, f_{1}\right]+\frac{1}{12}\left[f_{2},\left[f_{2}, f_{1}\right]\right]-\left[f_{2},\left[f_{2}, f_{1}\right]\right]-\frac{1}{24}\left[f_{1},\left[f_{2}, f_{2}, f_{1}\right]\right]+\ldots
$$

The remaining terms, involving four or more commutators, become quite numerous and no simple pattern is apparent. In practice, this formula is of interest in those cases where $f_{1}$ and $f_{\hat{2}}$ are small, and the series converges rapidly. Fortunately, this is the case for accelerators where nonlinearities are kept as small as possible so that the motion is very close to lnear. 


\subsection{LIE PRODUCT REPRESENTATION OF ACGEEERATOR LATTICES}

If we represent our accelerator by a combination of linear elements and nonlinear kicks, then the map for the lattice will be given by an expression of the form

$$
M=M_{N+1} e^{: f_{N}:} M_{N} e^{: f_{N-1}: \ldots} e^{: f_{2}:} M_{2} e^{i f_{1}:} M_{1}
$$

where the $M_{N}$ are linear operators and the $f_{n}=f_{n}\left(x_{n}, y_{n}\right)$ are multipole kicks at the longitudinal coordinate $s=s_{n}$. According to $\mathrm{Eq}$. (3.10), we may wite this product in terms of one set of variables by reversing the order of the products. We then have

$$
M=M_{1} e^{i f_{1}:} M_{2} e^{i f_{2}:} \ldots e^{i f_{N-1}:} M_{N} e^{i f_{N i}} M_{N+1}
$$

where all generators are now a function of the same (initial) variable. If we define $\bar{M}_{n}=\bar{M}_{1} \bar{M}_{2} \bar{M}_{3} \ldots \bar{M}_{n}$, then by inserting identities of the form $M_{n-1} \bar{M}_{n}$ into Eq. (3.15), and using the similarity relation, Eq. (3.15), many times we can transform Eq. (3.15) into the form

$$
M=e^{: \bar{M}_{1} f_{i}} e^{\bar{M}_{2} f_{2}}: \ldots e^{\bar{M}_{N-1} f_{N-1}:} e^{: \bar{M}_{R H} f_{N}: \bar{M}_{N+1}}
$$

The nonlinear kicks have been "rotated" to the front of the lattice. The $\bar{M}_{n}$ transform the initial variable to the variable at the location of the kick.

In the case that the map is a one-turn map for a circular machine, it is usual to introduce two similarity transformations, one which transiates the origin to the fixed point of the map, and the second which transforms the linear part of the map to a block diagonal rotation. If the origin is not a fixed point (one supposes it is close to the fixed point), the fixed point may be found by constructing the inverse to the map, and finding the image of the origin. Then the map

$$
\mathrm{T}_{\mathbf{a}}=e^{\text {:ata: }},
$$

where: $a \cdot z:=\sum_{i j} a_{i j} J_{i j} z_{j}$ and $J_{i j}$ is the symplectic form, will map the origin into the fixed point a. 
Let us suppose that the map of Eq. (3.16) has been translated if needed, so that it already maps the origin into itself. Let the matrix corresponding to the linear map $\bar{M}_{N+1}$ be $\widehat{M}$. Because $\widehat{M}$ is a symplectic matrix, it is possible to find eigenvahes which, if $\widehat{M}$ is stable, will lie on the unit circle and occur in pairs. Using the eigenvectors corresponding to these eigenvalues, we can construct a similarity transformation $\hat{A}_{0}$ with the property

$$
\widehat{\bar{M}}=\widehat{A}_{0} \widehat{P}_{\hat{R}}^{-1}
$$

where $\widehat{R}$ is a simple block rotation matrix

$$
\hat{R}=\left(\begin{array}{cc}
\hat{R}_{x} & 0 \\
0 & \hat{R}_{y}
\end{array}\right), \quad \widehat{R}_{x}=\left(\begin{array}{cc}
\cos \theta_{x} & \sin \theta_{x} \\
-\sin \theta_{x} & \cos \theta_{x}
\end{array}\right)
$$

We now insert these results into Dq. (3.16), remove the "n", to denote the corresponding Lie operator tather than the matrix, and additionaly introduce identities in the form $A_{0}^{-1} A_{0}$, so that we can move the $A_{0}^{-1}$ through the nonlinear kicks. We get

$$
M=A_{0}^{-1} e^{: A_{0} \bar{M}_{1} f_{1}} e^{: A_{0} \bar{M}_{2} f_{2}} \ldots e^{: A_{0} \bar{M} N f_{N}:} R A_{0}
$$

The functions

$$
\tilde{f}_{n}=A_{0} \bar{M}_{\pi n} f_{n}=\hat{f}_{n}\left(A_{0} \bar{M}_{n} \tilde{z}\right)
$$

are the functions $\vec{f}_{n}$ written in terms of the eigencoordinates at the longitudinal location $s \equiv s_{n}$. If there were no coupling present, then, for example,

$$
\begin{aligned}
x_{n} & =\vec{A}_{0} \vec{M}_{n} x \\
& =\sqrt{2 \beta_{x n} \vec{J}_{x}} \cos \left(\theta_{2}+\phi_{n n}\right)+\eta_{x n} \delta
\end{aligned},
$$

where $\beta_{n}, \phi_{n}, \eta_{n}$ are the usual beta function, phase advance and linear dispersion function at the point $s=s_{n}$, and the momentum deviation $\delta$ is defined by

$$
\delta \equiv \frac{p-p_{0}}{p_{0}},
$$

where $p 0$ is the monentum of a reference pariticle. 
At this point, we may drop the overall similarity transformation, $A_{0}$, and study the map

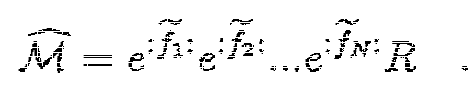

The Campbell-Baker-Hausdorf theorem, $\mathrm{Bq} \cdot(3.17)$, can be used to wite the result in a particularly simple form.

$$
\widehat{M}=e^{f: \hat{R}}
$$

Of course, $f$ is a generator which, in general, is diffcult to find, but the first terms in the perturbation series may be found quite easily, and one may hope that this will be adequate if the $\tilde{f}_{n}$ are small. We have

$$
f=\sum_{n=1}^{N} \widetilde{f}_{n}+\sum_{\substack{n \\ m<n}}^{N}\left[\widetilde{f}_{m}, \widetilde{f}_{n}\right]+\ldots
$$

\subsection{Lie Product NoRMal Form}

We now describe a process which is a generalization of the procedure introduced in Equs. (2.19) through (2.21). The map of Eq. (3.25) will distort the invariant phase space surfaces around the ofigin. For small actions these surfaces will be tori, the products of phase space circles in each phase space degree of freedom. As the action increases the invariant surfaces are slightly distorted. As the action increases further, the surfaces become only approximations to the actual motion, and eventually the concept of invariant surface breaks down entirely. We are interested in the regions that have invariant surfaces or approximate invariant surfaces and we would like to find such surfaces. If such surfaces exist, they will form an onion-like structure in phase space, and there will be a map that deforms the tori into these more conplicated shapes. Let such a map be noted 
by exp(: $g:)$. This map should satisfy an equation of the form

$$
\widehat{M}=e^{i f:}=e^{i g: \widetilde{R}} e^{-: g:}
$$

where $\widetilde{R}=R \exp (: \bar{h}:)$ is an amplitude dependent rotation in the toroidaly structured space. $h$ will be a function of the action variables only. $\widetilde{R}$ contains the information abott phase shirt whin ampltude, the operator expl: $g$ ) contains the information about the phase space distortion. The operator exp( $g$ ) will determine the smear. If Eq. (3.27) is indeed a valid equation, then we can move $R$ on the right-hand side to the right by inserting an $R R^{-1}$ on the right, and then use the Campbell-Baker-Hausdorf equation to find

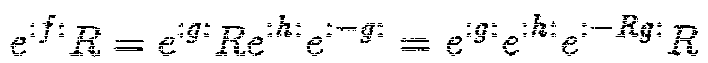

$$
\begin{aligned}
& =e^{(1-R) g+h=1 / 2[g, R g]-1 / 2[h,(1+R) g)+\cdots R} .
\end{aligned}
$$

Suppose that $f$ is given in the form

$$
f=\epsilon f_{1}+\epsilon^{2} f_{2}+\ldots
$$

and we wish to find a corresponding expression for $g$ and $h$ namely;

$$
\begin{aligned}
& g=\epsilon g_{1}+\epsilon^{2} g_{2}+\ldots \\
& h=\epsilon h_{1}+\epsilon^{2} h_{2}+\ldots
\end{aligned}
$$

Equating terms which are first order in $\epsilon_{;}$we get

$$
(1-R) g_{1}+h_{1}=f_{1}
$$

This may be solved uniquely by decomposing $f_{1}$ into two parts

$$
f_{\overline{1}}=f_{1}^{-}+f_{1}^{*}
$$


where $f_{1}^{-}$is the average of $f_{1}$ over phase angle, and $f_{1}^{*}=f_{1}-f_{1}^{-}$is the remainder. Then we may set

$$
h_{1}=f_{\underline{1}}^{-} \quad \text { and } \quad g_{1}=\frac{1}{1-\bar{R}} f_{1}^{*}
$$

The operator $1 /(1-R)$ is well defined on $f_{1}^{*}$ since the terms in $f_{1}$, which are independent of angle, have been removed.

Equating terms which are second order in $\epsilon$, we get the equation

$$
(1-R) g_{2}+h_{2}=f_{2}+\frac{1}{2}\left[g_{1}, R g_{1}\right]+\frac{1}{2}\left[h_{1},(1+R) g_{1}\right]
$$

We proced exactly as in Eqs. (3.31). There are two simplifications

$$
\begin{aligned}
{\left[h_{1},(1+R) g_{1}\right]^{-} } & =0 \\
{\left[g_{1}, R_{g}\right] } & =\left[\frac{1}{1-R} f_{1}^{*}, \frac{R}{1-R} f_{1}^{*}\right]=\left[f_{1}^{*}, \frac{1}{1-R} f_{1}^{*}\right]
\end{aligned}
$$

The result is

$$
\begin{aligned}
& h_{2}=f_{2}^{-}+\frac{1}{2}\left[f_{1}^{*}, \frac{1}{1-R} f_{1}^{*}\right]^{-} \\
& g_{2}=\frac{1}{1-f_{2}} f_{2}^{*}+\frac{1}{2}\left[f_{1}^{*}, \frac{1}{1-n_{1}} f_{1}^{*}+\frac{1}{2}\left[f_{1}^{-}, \frac{1+R}{1-R} f_{1}^{*}\right]\right.
\end{aligned}
$$

This procedure could be continued to higher orders.

\subsection{LIE ALGEBRAIC EXPRESTON POR TUNE SHIT AND SMEAR}

There are two sets of phase space angles one can discuss: one set is the original phase angles, the other set is the image of the first set under the map exp $(: g$ ). (Recall that in "local coordinates" the order of the factors in Eq $(3.27)$ is reversed.) The sane tune shift would result using either set, because a revointion traversed in one set implies a revolution traversed in the other set. The 
image of the original space under exp(: g:) we call the Floquet space, and the phase angles in this space the Floquet angles. The Eloquet angles are rotated by the operator $\tilde{R}$. Combining the operator expl: $h$;) with the operator $R=\exp \left(:-m_{0} \cdot J\right)$, we have

$$
\widetilde{R}=e^{i-10 \mathbb{j}+\bar{h}:}
$$

and the phase advance per turn is given by

$$
\mu_{i}(\mathfrak{S})=\mu_{\hat{m}}=\frac{\partial \bar{h}}{\partial J_{j}}
$$

The smear can be found by using exp(: $g$ :) to calculate the change in the actions: We have

$$
\bar{J}_{i}^{i}=e^{i-g *} \bar{J}_{i}
$$

hence,

$$
\Delta \bar{J}_{i}=e^{i-3 y_{i}}-\bar{J}_{i}
$$

The smear is found by taking the average over the angle of the square of this expression. If we are content with a first-order expression, then

$$
\Delta \bar{J}_{i}=-\frac{\partial g}{\partial \theta_{i}}=\frac{1}{R-1} \frac{\partial f_{1}^{*}}{\partial \theta_{i}}
$$

which is the same expression we found in Chapter 2.

\subsection{SECOND ORDER TUNE SHITS}

We now use Lie algebra techniques to calculate the second-order tune shifts. These are especially important for sextupoles and decapoles where the firstorder tune shifts are zero. 
The contributions to f from the normal sextupoles can be written

$$
f_{s}=\sum_{i=1} \alpha_{i} A_{2 i}+\frac{1}{2} \sum_{i<j} \alpha_{i} \alpha_{j}\left[A_{2 i}, A_{2 j}\right]
$$

where $\alpha_{i}$ is the strength of the $i^{\text {th }}$ sextupole (multiplied by the appropriate constants) and $A_{2 i}$ is the polynomial

$$
\begin{aligned}
& A_{2 i}=\frac{1}{3} x_{i}^{3}-x_{i} y_{i}^{2} \\
& x_{i} \equiv \bar{M}_{i} x=\sqrt{2 \beta_{x i} \bar{J}_{i}} \cos \left(\theta_{x}+\phi_{x i}\right)+\eta_{x i} \delta .
\end{aligned}
$$

We will calculate the tune shift for $\delta=0$. Then we may wite

$$
x_{i}=\sqrt{\frac{\beta_{x i} J_{x}}{2}}\left[e^{i\left(\theta_{x}+\phi_{x i}\right)}+c c\right]=\sqrt{\frac{\beta_{x i} J_{x}}{2}} F_{i}\left(e^{i \hat{\theta}_{x}}+c c\right)
$$

and $x_{i}^{\pi n}$ may be written as

$$
x_{\hat{\varepsilon}}^{n}=\left(\frac{\beta_{x i} \bar{\nu}_{x}}{2}\right)^{n / 2} R_{i}\left(e^{\mathrm{i} \hat{\phi}_{x}}+c c\right)^{n}
$$

We are using the notation that

$$
R_{i} f\left(\theta_{x}, \hat{\theta}_{y}\right)=f\left(\theta_{x}+\phi_{x^{i}}, \hat{\theta}_{y}+\phi_{y i}\right)
$$

for sextupoles, since $h_{1 s}=A_{2 s}=0, h_{i s}=A_{2 i}^{-}=0$

$$
h_{s}=h_{2 s}=\frac{1}{2} \sum_{i<j} \alpha_{i} \alpha_{j}\left[\hat{A}_{2 i}, \hat{A}_{2 j}\right]^{-}+\frac{1}{2} \sum_{i, j} \alpha_{i} \alpha_{j}\left[\hat{A}_{2 i,} \frac{1}{1-R} \hat{A}_{2 j}\right]^{-}
$$

This expression involves evaluation for $i \leq j$ of terms of the form

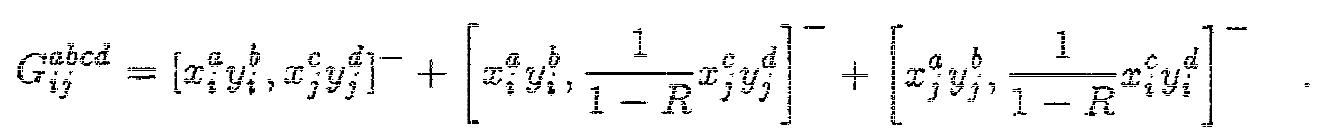


One can establish the following facts,

$$
\begin{aligned}
& {\left[x_{i}^{a} y_{i}^{b}, x_{j}^{c} y_{j}^{d}\right]^{-}=\sum_{\mathbf{n}} g_{i j}^{a b c d, \bar{z}} \sin \left(\mathbf{n} \cdot \phi_{i j}\right)}
\end{aligned}
$$

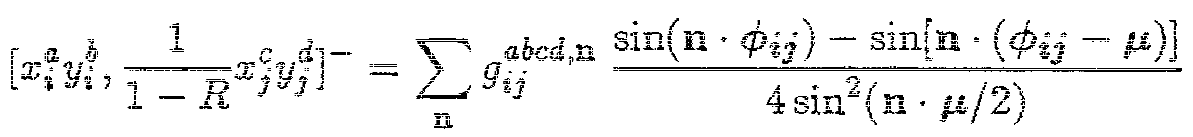

and

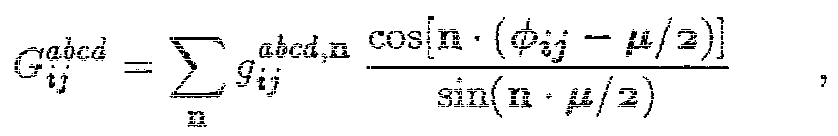

where

$$
\phi_{i}=\phi_{j}=\phi_{i}
$$

The term for $i=j$ would be obtained by taking the limit $j \rightarrow i$ and multiplying by $1 / 2$. This fact allows us to extend the sum over all $i$ and $j$ where now all terms have a factor of $1 / 2$. In this sum, we must replace $\phi_{i}$ by $\phi_{i j}^{+}$where

$$
\phi_{\dot{3} j}^{+}= \begin{cases}\phi_{i j}, & i<j \\ \phi_{j i}, & j<i\end{cases}
$$

Therefore, we ned only find the coeffichts of the first simple commutator above to get the $G_{i j}^{a b d}$, The combination of commutators is found by a simple replacement of the sine by another trigonometric function.

Note that only phase differences $\phi_{i j}$ arise. This follows from

$$
\left[R_{i f}, R_{j g}\right]^{-}=\left[f, R_{i}^{-1} R_{j}\right]^{-}=\left[f, R_{j i g}\right]^{-}
$$

where $R_{j i}=R_{j} R_{i}^{-1}$. To evaluate the commutators and find the $G_{i j}^{a b c d}$, one can use the basic commutator

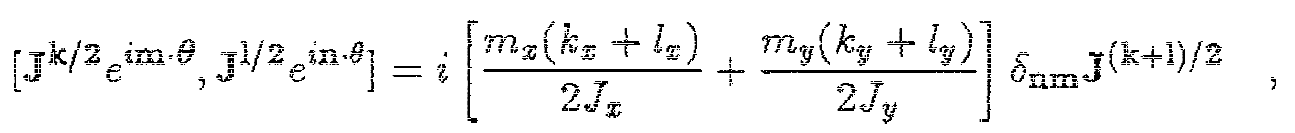

where $J^{k}=J_{x}^{k_{x}} J_{y}^{k_{y}}$ 
If we define

$$
T_{i j}^{\mathbf{n}} \equiv \frac{\cos \left[\mathbf{n} \cdot\left(\phi_{i j}^{+}-\mu / 2\right)\right]}{\sin (\mathbf{n} \cdot i / 2)}
$$

then the function $h_{s}$ is given by

$$
h_{s}=\frac{1}{4} \sum_{i j} \alpha_{i} \alpha_{j} \sum_{a b c d} d_{d b}^{b} d_{d i}^{b} \sum_{n} g_{i j}^{a b c d, n_{T} T_{i j}^{n}}
$$

where we have written

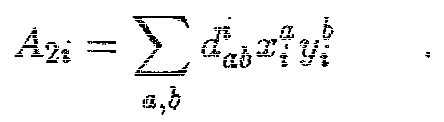

The appropriate coefficients $d_{a b}^{i}$ could be inserted for any multipole.

\section{Analytical Expressions for Tune Shift and Smear}

The formalimm outhed in Chapter 2 gives a recursive formulation for the calculation of ture shift and smear. It proves convenient to implement the recursive formulation in Chapter 2 using a computer algebra system MACSYMA. [15] This allows us to autonate the cumbersone anaytical forms corresponding to the higher order multipole contributions, as well as to generate the necessary FORTRAN code.

Generaly, MACSYMA programs have been written where the input is a definition of the vector potential and the output is analytical expressions for the smear and tune shifts; as well as PORTRAN-compatible expressions. Smear has been calculated to the first order in the multipole strength due to systematic or random $a_{2}, b_{2}, a_{3}, b_{3}$ and random $a_{4}$ and $b_{4}$. For random multipoles, the variance has also been calculated. Tune shifts have been calculated to the second order due to systematic $a_{2}, b_{2}, a_{3}$, and $b_{3}$. 


\subsection{SMAAR TO THE FIRST ORDER, IN TuE MULTPOLE STRENGTH}

If we define

$$
B_{j k}^{n_{x} \eta_{y}} \equiv \frac{\cos \left(\mathbf{n} \cdot \phi_{j k}\right)}{\sin ^{2}(\pi n \cdot \nu)}
$$

and

$$
A_{j}^{m_{x} m_{y}} \equiv\left(2 \beta_{x j} J_{x}\right)^{m_{x} / 2}\left(2 \beta_{y j} J_{y}\right)^{m_{y} / 2}
$$

we find

$$
\begin{aligned}
& S_{\bar{x}}^{2}=\frac{1}{\left(2 \bar{J}_{x}\right)^{2}} \sum_{j} \sum_{k}\left(\frac{1}{32} a_{2 j} a_{2 k} A_{j}^{21} A_{k}^{21}\left(B_{\bar{j} k}^{21}+B_{j k}^{2-1}\right)\right. \\
& +\frac{1}{128} b_{2 j} b_{2 k}\left[\left(4 A_{j}^{12} A_{k}^{12}-4 A_{j}^{30} A_{k}^{12}+A_{j}^{30} A_{k}^{30}\right) B_{j k}^{10}+A_{j}^{12} A_{k}^{12}\right. \\
& \times\left(B_{j k}^{12}+B_{j k}^{1-2}\right)+A_{j}^{30} A_{k}^{30} B_{j k}^{30} \\
& +\frac{1}{512} a_{3 j} a_{3 k}\left[A_{j}^{13} A_{k}^{13}\left(B_{j k}^{13}+B_{j k}^{1-3}+9 B_{j k}^{11}+9 B_{j k}^{1-1}\right)+9 A_{j}^{1} A_{k}^{31}\right. \\
& \left.\times\left(B_{j k}^{31}+B_{j k}^{3-1}+B_{j k}^{11}+B_{j k}^{1-1}\right)-18 A_{j}^{13} A_{k}^{31}\left(B_{j k}^{1}+B_{j k}^{1-1}\right)\right] \\
& +\frac{1}{512} b_{3 j} b_{3 k}\left[4\left(9 A_{j}^{22} A_{k}^{22}-6 A_{j}^{40} A_{k}^{22}+A_{j}^{40} A_{k}^{40}\right) B_{j k}^{20}+\hat{9} A_{j}^{22} A_{k}^{2 \hat{2}}\right. \\
& \left.\left.\times\left(B_{j k}^{22}+B_{j k}^{2-\hat{2}}\right)+A_{j}^{40} A_{k}^{40} B_{j k}^{40}\right\}\right) \\
& S_{y}^{2}=\frac{1}{\left(2 \bar{J}_{y}\right)^{2}} \sum_{j} \sum_{\bar{k}} \int \frac{1}{128} a_{2 j} a_{2 k}\left[\left(4 A_{j}^{21} A_{k}^{21}=4 A_{j}^{03} A_{k}^{21}+A_{j}^{03} A_{k}^{03}\right) B_{j k}^{01}\right. \\
& \left.+A_{j}^{21} A_{k}^{21}\left(B_{j k}^{21}+B_{j k}^{2-1}\right)+A_{j}^{03} A_{k}^{03} B_{j}^{03}\right] \\
& +\frac{1}{32} b_{2 j} b_{2 k} A_{j}^{12} A_{k}^{12}\left(B_{j k}^{12}+\bar{B}_{j k}^{1-2}\right) \\
& +\frac{1}{512} a_{3 j} a_{3 k}\left[A_{j}^{1 \hat{3}} A_{k}^{13}\left(B_{j k}^{1 \hat{3}}+B_{j k}^{1-\hat{3}}+B_{j k}^{11}+B_{j k}^{1-1}\right)+A_{j}^{31} A_{k}^{31}\right. \\
& \left.\times\left(B_{j k}^{31}+B_{j k}^{3-1}+9 B_{j k}^{11}+9 B_{j k}^{1-1}\right)=18 A_{j}^{13} A_{k}^{31}\left(B_{j k}^{11}+B_{j k}^{1-1}\right)\right] \\
& +\frac{1}{512} b_{3 j} b_{3 k}\left[A_{2}\left(0 A_{j}^{22} A_{k}^{22}-6 A_{j}^{22} A_{k}^{04}+A_{j}^{04} A_{k}^{04}\right) B_{j k}^{02}+9 A_{j}^{22} A_{k}^{22}\right. \\
& \left.\left.\times\left(B_{j k}^{22}+\bar{B}_{j k}^{2-2}\right)+A_{j}^{04} A_{\bar{k}}^{04} \bar{B}_{j k}^{0 i}\right]\right\} .
\end{aligned}
$$


For systematic multipoles, the sums run over one cell; $y$ in the denominator of Eq. (4.1) is the phase advance per cell divided by $2 \pi$. For random multipoles, the rms smear is obtained by averaging over random seeds so that

$$
\left\langle a_{n j} a_{n k}\right\rangle_{\text {seeds }} \rightarrow \sigma_{a_{j} n}^{2} b_{j h}, \quad\left\langle b_{n j} b_{n h}>_{\text {seeds }} \rightarrow \sigma_{b_{j} n}^{2} \hat{o}_{j h}\right.
$$

where $\sigma_{a_{n}}, \sigma_{b_{n}}$ are the rms values of the multipole strengh. The random multipole errors are assumed to be uncorrelated. Each sum runs over the whole lattice and the phase advance for the entire latice divided by $2 \pi$ should be used in Eq. (4.1). However, since the beta tunctions are periodic with the cell, the sums simplify to a sum over one cell multiplied by the number of cells.

\subsection{TUNE SHFTS TO THE FIRST ORDER IN THE MULTPOEE STRENGTH}

To the first order, only quadripole and octupole errors contribute to the tune shifts (if higher order multipoles are neglected). We have

$$
\begin{aligned}
& \Delta \nu_{z}=\frac{1}{2 \pi} \sum_{j}\left[\frac{1}{2} b_{1 j} \beta_{x j}+\frac{3}{4} \bar{b}_{3 j}\left(\beta_{x j}^{2} J_{x}-2 \beta_{x j} \beta_{y j} \bar{J}_{y}\right)\right] \\
& \Delta \hat{\nu}_{y}=\frac{1}{2 \pi} \sum_{j}\left[-\frac{1}{2} b_{1 j} \beta_{y j}-\frac{3}{4} b_{3 j}\left(2 \beta_{x j} \beta_{y j} J_{x}-\beta_{y j}^{2} J_{y}\right)\right]
\end{aligned}
$$

where for systematic errors, the sum runs over one cell and should be multipled by the number of cells. 


\subsection{SECOND ORDER TUNE SHITS}

We find for the second order tune shifts

$$
\begin{aligned}
& \Delta v_{x}=\frac{1}{2 \pi} \sum_{j} \sum_{k}\left(\frac{1}{8} a_{1 j} a_{i k} \sqrt{\beta_{x j} \beta_{x k} \beta_{y j} \beta_{y k}}\left(T_{j k}^{1-1}-T_{j k}^{11}\right)\right. \\
& +\frac{1}{8} a_{2 j} \alpha_{2 k}\left[4\left(-\beta_{x j} \beta_{x k} \sqrt{\beta_{y j} \beta_{y k}} J_{x}+\beta_{x j} \sqrt{\beta_{y j}} \beta_{y k}^{3 / 2} J_{y}\right) T_{j k}^{0 !}-\beta_{x j} \beta_{x k} \sqrt{\beta_{y j} \beta_{y k}}\right. \\
& \left.\times\left(J_{x}+2 J_{y}\right) T_{j k}^{21}+\beta_{x j} \beta_{x k} \sqrt{\beta_{y j} \beta_{y k}}\left(J_{x}-2 J_{y}\right) T_{j k}^{2-1}\right] \\
& +\frac{1}{8} b_{2 j} b_{2 k}\left[\left(-3 \beta_{x j}^{3 / 2} \beta_{z k}^{3 / 2} J_{x}+4 \sqrt{\beta_{x j}} \beta_{x k}^{3 / 2} \beta_{y j} J_{y}\right) T_{j k}^{10}-\beta_{x j}^{3 / 2} \beta_{x k}^{3 / 2} J_{x} T_{j k}^{30}\right. \\
& \left.+2 \sqrt{\beta_{x j} \beta_{x k}} \beta_{y j} \beta_{y k} J_{y}\left(T_{j k}^{1-2}-T_{j k}^{12}\right)\right]
\end{aligned}
$$

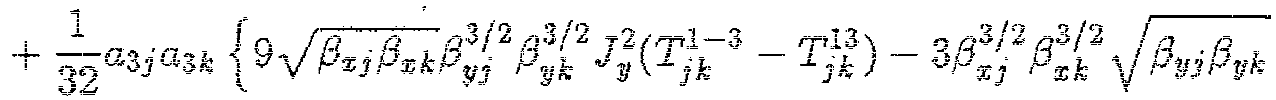

$$
\begin{aligned}
& \times\left(J_{x}^{2}+6 J_{x} J_{y}\right) T_{j k}^{31}+3 \beta_{x j}^{3 / 2} \beta_{x k}^{3 / 2} \sqrt{\beta_{y j} \beta_{y k}}\left(J_{x}^{2}-6 J_{x} J_{y}\right) T_{j k}^{3-1}+[(-27
\end{aligned}
$$

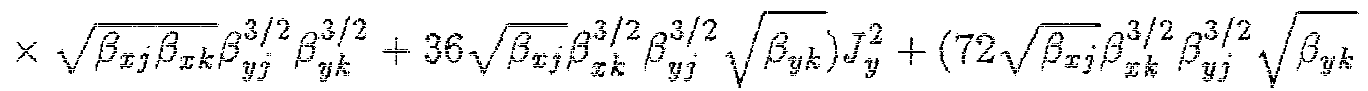

$$
\begin{aligned}
& -54 \beta_{x j}^{3 / 2} \beta_{x k}^{3 / 2} \sqrt{\left.\beta_{y j} \beta_{y k}\right) J_{x} J_{y}}-27 \beta_{x j}^{3 / 2} \beta_{x k}^{3 / 2} \sqrt{\left.\beta_{y j} \beta_{y k} J_{x}^{2}\right] T_{j k}^{11}}+[(27
\end{aligned}
$$

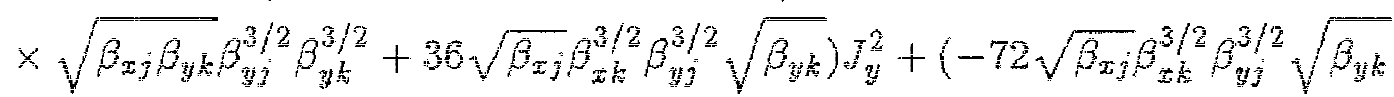

$$
\begin{aligned}
& \left.\left.-54 \beta_{x j}^{3 / 2} \beta_{x \bar{k}}^{3 / 2} \sqrt{\beta_{y j} \beta_{y k}}\right) \bar{J}_{x} \bar{J}_{y}+27 \beta_{x j}^{3 / 2} \beta_{x \bar{k}}^{3 / 2} \sqrt{\beta_{y j} \beta_{y k}} \bar{J}_{x j}^{2} \bar{T}_{j k}^{1-1}\right] \\
& +\frac{1}{32} b_{3 j} b_{3 i}\left\{-9 \beta_{x j} \beta_{x k} \beta_{y j} \beta_{y k}\left(\overline{2} J_{z} \bar{J}_{y}+\bar{J}_{y}^{2}\right) T_{j k}^{22}+9 \beta_{x j} \beta_{x k} \beta_{y j} \beta_{y k}\left(\overline{2} J_{x} J_{y}\right.\right. \\
& \left.-J_{y}^{2}\right) T_{j k}^{2}-2-3 \beta_{x j}^{2} \beta_{x k}^{2} J_{z}^{2} T_{j k}^{40}+36 \beta_{x j} \beta_{y j} \beta_{y k}^{2} J_{y}^{2} T_{j k}^{02}-36 \beta_{x j} \beta_{x k} \beta_{y j} \beta_{y k} J_{y}^{2} T_{j k}^{20} \\
& \left.\left.+72 \beta_{x j} \beta_{x k}^{2} \beta_{y j} J_{x} J_{y} T_{j k}^{20}-72 \beta_{x j} \beta_{x k} \beta_{y j} \beta_{y k} J_{x} J_{y} T_{j k}^{02}-24 \beta_{x j}^{2} \beta_{x k}^{2} J_{x}^{2} T_{j k}^{20}\right)\right)
\end{aligned}
$$




$$
\begin{aligned}
& \Delta \nu_{y}=\frac{1}{2 \pi} \sum_{j} \sum_{k}\left(-\frac{1}{8} a_{1 j} a_{1 k} \sqrt{\beta_{x j} \beta_{x k} \beta_{y j} \beta_{y k}}\left(T_{j k}^{1-1}+T_{j k}^{11}\right)\right. \\
& +\frac{1}{8} a_{2 j} a_{2 k}\left[\left(4 \beta_{x j} \sqrt{\beta_{y j}} \beta_{y k}^{3 / 2} J_{x}-3 \beta_{y j}^{3 / 2} \beta_{y k}^{3 / 2} J_{y j}\right) T_{j k}^{01}+2 \beta_{z j} \beta_{x k} \sqrt{\beta_{y j} \beta_{y k}} J_{x}\right. \\
& \left.\times\left(T_{j k}^{2-1}-T_{j k}^{21}\right)-\beta_{y j}^{3 / 2} \beta_{y k}^{3 / 2} J_{y j} T_{j k}^{03}\right] \\
& +\frac{1}{8} b_{2 j} b_{2 k}\left[\frac{\Delta}{x}\left(\sqrt{\beta_{x j}} \beta_{x k}^{3 / 2} \beta_{y j} J_{x}-\sqrt{\beta_{x j} \beta_{x k}} \beta_{y j} \beta_{y k} \bar{J}_{y}\right) T_{j k}^{10}-\sqrt{\beta_{x j} \beta_{x k}} \beta_{y j} \beta_{y k}\right. \\
& \left.\times\left(2 J_{j}+J_{y}\right) T_{j k}^{12}-\sqrt{\beta_{\bar{x} j} \beta_{x k}} \beta_{y j} \beta_{y k}\left(2 J_{x}-J_{y}\right) T_{j k}^{1-2}\right] \\
& +\frac{1}{32} a_{3 j} a_{3 k}\left\{-9 \beta_{z j}^{3 / 2} \beta_{z k}^{3 / 2} \sqrt{\beta_{y j} \beta_{y k} J_{z}^{2}}\left(T_{j k}^{3-1}+T_{j k}^{31}\right)+3 \sqrt{\beta_{x j} \beta_{x k}} \beta_{y j}^{3 / 2} \beta_{y k}^{3 / 2}\right. \\
& \times\left(6 J_{y} J_{y}-J_{y}^{2}\right) T_{j k}^{1-3}-3 \sqrt{\beta_{x j} \beta_{x k}} \beta_{y j}^{3 / 2} \beta_{y 2}^{3 / 2}\left(6 J_{x} J_{y}+J_{y}^{2}\right) T_{j k}^{13}+[-27 \\
& \times \sqrt{\beta_{x k} \beta_{x k}} \beta_{y j}^{3 / 2} \beta_{y \hat{k}}^{3 / 2} J_{y}^{3}+\left(-54 \sqrt{\beta_{x j} \beta_{x k}} \beta_{y j}^{3 / 2} \beta_{y j k}^{3 / 2}+72 \sqrt{\beta_{x j}} \beta_{x h}^{3 / 2} \beta_{y j}^{3 / 2}\right.
\end{aligned}
$$

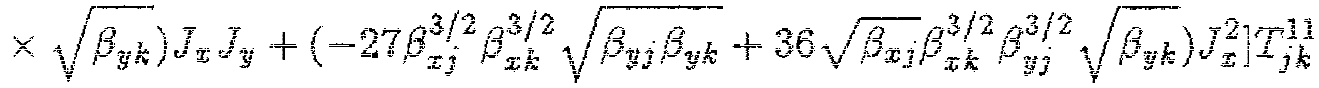

$$
\begin{aligned}
& +\left[-27 \sqrt{\beta_{x j} \beta_{x k}} \beta_{y j}^{3 / 2} \beta_{y / 2}^{3 / 2} J_{y}^{2}+\left(54 \sqrt{\beta_{x j} \beta_{x k}} \beta_{y j}^{3 / 2} \beta_{y k}^{3 / 2}+72 \sqrt{\beta_{x j} \beta_{z h}^{3 / 2} \beta_{y j}^{3 / 2}}\right.\right.
\end{aligned}
$$

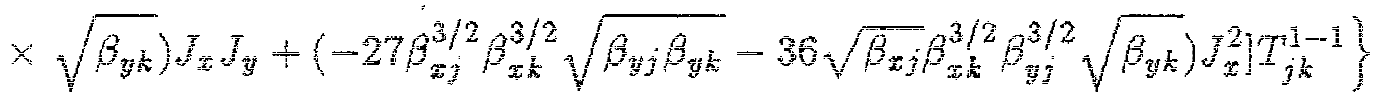

$$
\begin{aligned}
& +\frac{1}{32} b_{3 j} b_{3 k}\left(-9 \beta_{x j} \beta_{x h} \beta_{y j} \beta_{y k}\left(2 J_{x} J_{y}+J_{y}^{2}\right) T_{j k}^{22}-9 \beta_{x j} \beta_{x h} \beta_{y j} \beta_{y j}\left(2 J_{x} J_{y}-J_{x}^{2}\right)\right. \\
& \times T_{j k}^{2-2}-3 \beta_{x j}^{2} \beta_{x k}^{2} j_{y j}^{2} T_{j k}^{04}-24 \beta_{y j}^{2} \beta_{y k}^{2} j_{y j}^{2} T_{j k}^{02}+72 \beta_{x j} \beta_{y j} \beta_{y k}^{2} J_{z} J_{y j} T_{j k}^{02}
\end{aligned}
$$

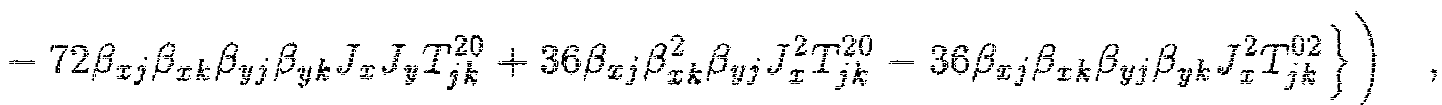

where $T_{j k}^{\hat{n}_{x} \hat{n}_{y}}$ is defined by $\mathrm{Fq} .(3.55)$

For systematic errors, each sum runs over one cell and should be multiplied by the number of cells. In $E a .(3.55)$, the phase advance for one cell divided by $2 \pi$ should be used for $\nu$. 


\section{Closed Orbit Perturbations}

By realizing that a reasonable correction scheme for closed orbit distortions should lead to local corrections, we conclude that the final corrected orbit can be calculated locally. This can then be done by using the well-known matrix formalism. [7]

\subsection{CALOULATON OF THE CLOSED ORBT DISTORTONS}

We will assume that a lattice cell for SSC has one horizontal dipole corrector and beam positron monitor (bpm) at each horizontally focusing quadrupole and vice versa for the vertical plane. The ultimate result of the correction scheme is to make the corrected orbit pass through the center of the bpm's. Since there are also bpm errors, this orbit will normally differ from the design orbit.

The calculations will be split in two parts. First, we assime the bprin errors to be zero and calculate the orbit due to dipole errors and quadrupole displacements. The contributions from higher multipoles will be neglected. In the second part, we assume the mutipole errors to be zero and calculate the orbit due to the bpm errors. This split car be done since the bpm errors are assumed to be uncorrelated with the multipole errors.

The transfer matrix between two arbitrary points $s_{0}$ and $s_{1}$ along a latice

$$
\left(\begin{array}{l}
x_{1} \\
x_{1}^{i}
\end{array}\right)=\vec{M}\left(\begin{array}{l}
x_{0} \\
x_{0}^{i}
\end{array}\right)
$$

where

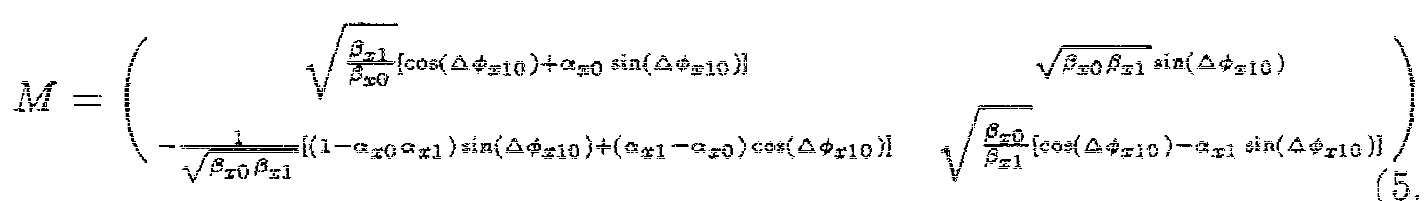

and

$$
\phi_{x 10} \equiv \phi_{x 1}-\phi_{x 0}
$$


If there are no bpm errors, the effect of the correctors is to make the orbit distortions zero at the bpm's (which were assumed to be at the correctors) so that

$$
\Delta x_{n}=\Delta x_{0}=0 .
$$

If we use the thin lens approximation for the errors and the correctors, we find from $\mathrm{Egs} \cdot(5.2)$ and $(5.4)$

$$
\Delta x_{n}=\sqrt{\beta_{x n} \beta_{x 0}} \sin \left(i k_{x}^{c b^{i}}\right) \cdot \Delta x_{0}^{i}+\sum_{i=1}^{n-1} \sqrt{\beta_{x n} \beta_{x l}} \sin \left(\Delta \phi_{x n}\right) \cdot \Delta x_{l}^{i}=0
$$

or

$$
\Delta x_{0}^{i}=-\sum_{i=1}^{n-1} \sqrt{\frac{\beta_{x i}}{\beta_{x i}}} \frac{\sin \left(\Delta \phi_{x n l}\right)}{\sin \left(\mu_{x}^{c e l l}\right)} \Delta x_{l}^{\prime}
$$

where

$$
\Delta x_{i}^{i}=-b_{d}\left(b_{0}+b_{1} \Delta x_{\text {oquad }}\right)
$$

and $\Delta x_{\text {quad }}$ is the quadrupole misalignment, since higher order multipoles are neglected. By using

$$
\Delta x_{j}=\sum_{i=0}^{<j} \sqrt{\beta_{x j} \beta_{x l}} \sin \left(\Delta \dot{\phi}_{x j}\right) \cdot \Delta x_{i}^{\prime}, \quad 0 \leq j \leq n
$$

we find

$$
\begin{aligned}
\Delta x_{j}= & -\sum_{i=1}^{<j} \sqrt{\beta_{x j} \beta_{x i}} \sin \left(\Delta \phi_{x j 0}\right) \cdot \frac{\sin \left(\Delta \phi_{x n l}\right)}{\sin \left(\mu_{x}^{c e l l}\right)} \cdot \Delta x_{l}^{i} \\
& +\sum_{i=1}^{<j} \sqrt{\beta_{x j} \beta_{x i}} \sin \left(\Delta \phi_{x j l}\right)=x_{i}^{i}
\end{aligned}
$$


By using some trigonometric relations, this can be written

$$
\begin{aligned}
& \Delta x_{j}^{m \bar{p}}=-\frac{1}{\sin \left(\mu_{x}^{c e l l}\right)}\left[\sum_{i=1}^{<j} \sqrt{\beta_{x j} \beta_{x i}} \Delta x_{l}^{\prime} \sin \left(\Delta \phi_{x n_{j}}\right) \sin \left(\Delta \phi_{x i 0}\right)\right. \\
& \left.+\sum_{i=j}^{n-1} \sqrt{\beta_{x i} \beta_{x i}} \Delta x_{i}^{i} \sin \left(\Delta \phi_{x, j}\right) \sin \left(\Delta \phi_{m n}\right)\right], \quad 0 \leq j \leq n
\end{aligned}
$$

We now assume the multipole errors to be zero and that the correctors have been adjusted so that the new orbit passes through the centers of the bon's. From Eq. (5.2), we have

$$
\begin{aligned}
\Delta x_{n}= & \sqrt{\frac{\beta_{x n}}{\beta_{x 0}}}\left[\cos \left(\Delta \phi_{x n 0}\right)+\alpha_{x 0} \sin \left(\Delta \phi_{x n 0}\right)\right] \Delta x_{0} \\
& +\sqrt{\beta_{x n} \beta_{x 0}} \sin \left(\Delta \phi_{x n 0}\right) \cdot \Delta x_{0}^{\prime}
\end{aligned}
$$

The $\beta$-function is periodic, hence

$$
\beta_{x r_{0}}=\beta_{x 0}
$$

so that

$$
\left.\Delta x_{0}^{\prime}=\frac{1}{\rho_{x 0} \sin \left(\mu_{x}^{c e l l}\right)}\left\{\Delta x_{x}-\left[\cos \left(\mu_{x}^{c e l l}\right)+\alpha_{x}^{0} \sin \left(\mu_{x}^{c e l l}\right) \Delta x_{0}\right]\right\}\right] .
$$

In a similar way, we obtain

$$
\Delta x_{j}^{\mathrm{bpm}}=\frac{1}{\sin \left(\mu_{x}^{\text {cell }}\right)} \sqrt{\frac{\beta_{x_{\hat{j}}}}{\beta_{x 0}}}\left[\sin \left(\Delta \phi_{x n j}\right) \cdot \Delta x_{0}+\sin \left(\Delta \phi_{x j 0}\right) \cdot \Delta x_{n j}\right]
$$

Since we assume the multipole misalignment and bpm displacement errors to be uncorrelated, we finaly obtain

$$
\Delta x_{j}^{c o}=\sqrt{\left(\Delta x_{j}^{m p}\right)^{2}+\left(\Delta x_{j}^{b p m}\right)^{2}} .
$$




\subsection{CAICULATION OF THE FEED-DOWN}

The feed-down is calculated by generalizing $\mathrm{Eq} \cdot(2,23)$ to

$$
V=\theta_{a} \bar{R}_{e} \sum_{n=0}^{\infty} \frac{1}{n+1}\left(b_{n}+i a_{n}\right)[x+\Delta x+i(y+\Delta y)]^{n+1}
$$

where $\Delta x$ and $\Delta y$ is the horizontal and vertical orbit. If we restrict ourselves to terms linear in $\Delta x$ or $\Delta y$, we find the following contributions from the feed-down

$$
\begin{aligned}
& a_{n-1}=n\left(a_{n} \Delta x+b_{n} \Delta y\right)+O(2) \\
& b_{n-1}=-n\left(a_{n} \Delta y-b_{n} \Delta x\right)+O(2) .
\end{aligned}
$$

This approximation is expected to be good as long as $\Delta x \ll A_{x}$ and $\Delta y \ll A_{y}$. When these terms are inserted in the equations for $S^{2}$, Eqs. (4.3), and we average over random seeds, we find

$$
\begin{aligned}
\hat{b}_{n j} b_{n k} & \sim a_{(n+1), j} a_{(n+1), k}<\Delta y_{j} \Delta y_{k}>_{\text {seed }} \\
& +b_{(n+1), j} b_{(n+1), k}<\Delta x_{j} \Delta x_{k}>_{\text {seeds }}+O(2)
\end{aligned}
$$

for systematic multipoles and

$$
\left.\left\langle b_{n j} b_{n k}\right\rangle_{\text {seeds }} \sim\left[\sigma_{a_{(n+1), j}}^{2}<\Delta y_{j}^{2}\right\rangle_{\text {seeds }}+\sigma_{b_{(n+1), j}^{2}}^{2}<\Delta x_{j}^{2}>_{\text {seeds }}\right] \delta_{j k}+O(2)
$$

for random multipoles, since $\Delta x, \Delta y$ and the multipole errors are assumed to be uncorrelated. The correlations $\left\langle\Delta x_{j} \Delta x_{k}\right\rangle_{\text {seeds }}$ and $\left\langle\Delta y_{j} \Delta y_{k}\right\rangle_{\text {seeds }}$ are calculated from Eq. (5.10). 


\section{Chromatic Perturbations}

The chromatic pertubations can be treated as a feed-down where the orbit is given by the nonlinear dispersion function $\eta$

$$
\Delta x=\hat{o}=\delta\left(\eta_{0}+\hat{b}+\ldots\right)
$$

where $\eta_{0}$ is the linear dispersion function. Furthermore, the multipole strength is replaced by an effective multipole strength given by

$$
b_{n}=\frac{1}{1+\delta} b_{n}=\left(1-\delta+\delta^{2}-\ldots\right) b_{n}
$$

Since the linear chromaticity is corrected, one would hke to calculate the chromaticity to at least quadratic terms in $\hat{f}$. From above, it is, however, clear that, this requires a lnowledge of $\eta_{1}$. It can be calculated, [16] but a direct numenical calculation of the ture shit using map techniques would be more efficient. [17] The previous work has, therefore, been limited to the on-momentum case.

\section{Numerical Results}

In the expressions for the smear, Eqs. (4.3), we find terms proportional to

$$
\begin{aligned}
& \frac{1}{\sin ^{2}(\pi \nu)} \\
& \frac{1}{\sin ^{2}(\pi 2 \nu)}
\end{aligned}
$$

from sextupoles and the octupoles. The first case may be interpreted as orbit terms and the second will only change the average amplitude. Since the perturbations of these terms is similar to dipole and quadrupole perturbations (but amplitude dependent) and to simplify the analysis of the tracking data, they have been excluded in the following calculations. 
We have studied FODO-lattices with identical approximately 90 degree cells for an injection energy of 1 or $2 \mathrm{TeV}, 4$ or $5 \mathrm{~cm}$ magnet aperture and injection optics.

Table 1: Studied cases.

\begin{tabular}{|c|c|c|c|c|c|c|c|c|}
\hline \multirow{2}{*}{$\begin{array}{l}\text { No of dipoles } \\
\text { per half cell }\end{array}$} & \multirow{2}{*}{$\begin{array}{l}\text { Half cell } \\
\text { length }\end{array}$} & \multirow{2}{*}{$\begin{array}{l}\text { No. of } \\
\text { cells }\end{array}$} & \multirow[t]{2}{*}{$\ddot{y}_{x}$} & \multirow[t]{2}{*}{$y_{i y}$} & \multicolumn{2}{|c|}{$A_{i s}=A_{i j}(\mathrm{~mm})$} & \multicolumn{2}{|c|}{$\delta\left(10^{-3}\right)$} \\
\hline & & & & & $\mathrm{ITeV}$ & $2 \operatorname{TeV}$ & $1 \mathrm{TeV}$ & $2 \mathrm{TeV}^{\prime}$ \\
\hline \multirow[t]{2}{*}{4} & 84.20 & 480 & 121.285 & 122.265 & 4.15 & 3.73 & 0 & 0 \\
\hline & & & & & 2.75 & 2.35 & 1.36 & 0.68 \\
\hline \multirow[t]{2}{*}{5} & 98.62 & 384 & 97.285 & 98.265 & 4.43 & 3.97 & 0 & 0 \\
\hline & & & & & 2.92 & 2.46 & 1.18 & 0.58 \\
\hline \multirow[t]{2}{*}{6} & 114.25 & 320 & 81.285 & 82.265 & $4 . \overline{7}$ & 4.18 & 0 & 0 \\
\hline & & & & & 3.10 & 2.55 & 1.0 & 0.50 \\
\hline
\end{tabular}

Tole Mulpole exors in the dipoles.

\begin{tabular}{|c|c|c|c|c|c|c|}
\hline \multirow[b]{2}{*}{ Multipole } & \multicolumn{2}{|c|}{ Random errors } & \multicolumn{4}{|c|}{ Systematic errors } \\
\hline & ${ }_{n}^{i} \mathrm{~cm}$ & $5 \mathrm{~cm}$ & $1 \mathrm{TeV}, 4 \mathrm{~cm}$ & $1 \mathrm{TeV}, 5 \mathrm{~cm}$ & $2 \mathrm{Tbv}, 4 \mathrm{~cm}$ & $2 \mathrm{TeV}, 5 \mathrm{~cm}$ \\
\hline as & 6.0 & 6.0 & 0 & 0 & 0 & 0 \\
\hline$b_{0}$ & 6.0 & 6.0 & 0 & 0 & 0 & 0 \\
\hline$a_{1}$ & $0 . \overline{7}$ & 0.56 & 0.2 & 0.2 & 0.15 & 0.15 \\
\hline$b_{1}$ & 0.7 & 0.56 & 0.2 & 0.2 & 0.15 & 0.15 \\
\hline$E_{2}$ & 0.6 & 0.41 & 0.1 & 0.1 & 0.06 & 0.06 \\
\hline$b_{2}$ & 0.4 & 0.27 & -8.4 & -4.0 & -5.39 & -2.53 \\
\hline$a_{3}$ & 0.7 & 0.41 & 0.2 & 0.2 & 0.11 & 0.11 \\
\hline$b_{3}$ & 0.3 & 0.18 & 0.1 & 0.1 & 0.05 & 0.05 \\
\hline$a_{4}$ & 0.2 & 0.10 & 0.2 & 0.2 & 0.00 & 0.09 \\
\hline$\hat{b}_{4}$ & 0.7 & 0.35 & 0.84 & 0.5 & 0.38 & 0.18 \\
\hline
\end{tabular}

The total number of dipoles has been kept to 3840 , but the number of dipoles per cell and the number of cells have been varied. The cases that have been 
studied are shown in Table $1 .[11,18]$ Closed orbit distortions have been calculated for

$$
\Delta x_{\mathrm{quad}}^{\mathrm{rms}}=1.00 \mathrm{~mm} ; \quad \Delta x_{\mathrm{bpm}}^{\mathrm{Fms}}=1.41 \mathrm{~mm}
$$

with respect to the design orbit. The linear aperture may be defined by $6.4 \%$ smear [4] and a tune shift of $5 \times 10^{-3}$. [1] The linear lattice functions were calcilated by TEAPOT. [19] After the systematic multipole errors had been added, the linear chromaticity was tuned to zero using TIAPOT. The strength obtained for the chromaticity sextupoles were then used in the analytical calculations. Calculations have also been done with the "SNEUFF" correction scheme. [1] In this case, the chromaticity was tured after the the correctors had been added. Correctors were added for $a_{2}, b_{2}, a_{3}$, and $b_{3}$.

\subsection{SMEA AND TUNE SHTTS}

In Tables 3 to 15 , we present the smear and tune shifts for the different cases specifed in Table 1. For random multipoles, we give the average smear and the spread of the total smear as defined by Eqs. (2.2) and (2.3). An empty location indicates that no value has ben calculated. Linear coupling perturbations due to feed-down in the sextupoles are presented (in the column $\left(a_{1}\right)$ ), but are not included in the total. The total tune shifts are obtaned by sumining the individual terms, whereas for the total smear one has to sum the square of the different contributions and then take the square root. Note that if the linear lattice functions are given, the results in one of the tables displayed below, is obtained in less than a minute on the VAX.

Table 3 shows a case when the horizontal and verical tune have not been splitted by one unit $\left(\nu_{x}=81.285, \quad t_{y}=81.265\right)$. As expected, this leads to very high contribution from the systematic errors. 
Table 9a: 6 dipoles, 1 TeV, 4 cm magnet aperture, no split.

\begin{tabular}{|c|c|c|c|c|c|c|c|c|}
\hline Smear (\%) & $\left(a_{1}\right)$ & $\pi_{2}$ & $b_{2}$ & $a_{3}$ & $b_{3}$ & $a_{\hat{4}}$ & $b_{\text {舫 }}$ & Total \\
\hline Due to random multipoles & & $\begin{array}{l}1.4 \\
1.0\end{array}$ & 0.8 & $\begin{array}{l}2.3 \\
2.4\end{array}$ & $\begin{array}{l}0.5 \\
0.6\end{array}$ & 0.1 & $\begin{array}{l}0.2 \\
0.2\end{array}$ & $\begin{array}{l}2.9 \pm 0.8 \\
2.8 \pm 0.6\end{array}$ \\
\hline $\begin{array}{l}\text { Due to feed-down in the } \\
\text { random multipoles }\end{array}$ & $\begin{array}{l}6.2 \\
6.2\end{array}$ & $\begin{array}{l}0 . \overline{8} \\
0.4\end{array}$ & $\begin{array}{l}0.4 \\
0.6\end{array}$ & $\begin{array}{l}1.0 \\
1.1\end{array}$ & 0.5 & & & $\begin{array}{l}1.3 \\
1.4\end{array}$ \\
\hline Due to systematic multipoles & & 0.0 & $\begin{array}{l}1.0 \\
0.5\end{array}$ & $\begin{array}{l}0.1 \\
0.1\end{array}$ & $\begin{array}{l}8.0 \\
8.0\end{array}$ & & & $\begin{array}{l}8.1 \\
8.0\end{array}$ \\
\hline $\begin{array}{l}\text { Due to feed-down in the } \\
\text { systematic multipoles }\end{array}$ & 66.1 & 0.5 & $\begin{array}{l}0.2 \\
0.4\end{array}$ & $\begin{array}{l}1.0 \\
1.2\end{array}$ & $\frac{1.4}{1.5}$ & & & $\frac{1}{2.8}$ \\
\hline $\begin{array}{l}\text { Due to corrected } \\
\text { systematic multipoles }\end{array}$ & & 0.0 & 0.5 & $\begin{array}{l}0.6 \\
0.6\end{array}$ & $\begin{array}{l}0.1 \\
0.1\end{array}$ & & & $\begin{array}{l}0.8 \\
0.7\end{array}$ \\
\hline $\begin{array}{l}\text { Due to feed-down in the } \\
\text { cort. systematic multipoles }\end{array}$ & $\begin{array}{l}27.5 \\
27.5\end{array}$ & $\begin{array}{l}0.1 \\
0.1\end{array}$ & $\begin{array}{l}0.1 \\
0.0\end{array}$ & $\begin{array}{l}0.0 \\
0.0\end{array}$ & $\begin{array}{l}0.3 \\
0.3\end{array}$ & & & $\begin{array}{l}0.4 \\
0.3 \\
\end{array}$ \\
\hline$\Delta \nu\left(10^{-3}\right)$ & $a_{2}^{\frac{2}{2}}$ & $b_{2}^{2}$ & $b_{3}$ & $a_{3}^{2}$ & $b_{3}^{2}$ & & & Total \\
\hline Due to systematic multipoles & 0.0 & $\begin{array}{l}22.5 \\
31.1\end{array}$ & $\begin{array}{l}-2.4 \\
-2.4\end{array}$ & $\begin{array}{r}-29.9 \\
29.8\end{array}$ & $\begin{array}{l}0.6 \\
-0.6\end{array}$ & & & $\begin{array}{l}-9.2 \\
57.0\end{array}$ \\
\hline $\begin{array}{l}\text { Due to corrected } \\
\text { systematic mulipoles }\end{array}$ & 0.0 & $\begin{array}{l}6.4 \\
6.1\end{array}$ & 0.2 & 0.0 & $\begin{array}{l}0.0 \\
0.0\end{array}$ & & & $\begin{array}{l}6.5 \\
6.3\end{array}$ \\
\hline
\end{tabular}

Table $\bar{b}: 6$ dipoles, 1 TeV, 4 crimagnet aperture.

\begin{tabular}{|c|c|c|c|c|c|c|c|c|}
\hline Smear $(\%)$ & $\left(a_{1}\right)$ & $a_{3}$ & $b_{2}$ & $a_{3}$ & $b_{3}$ & $a_{4}$ & $b_{4}$ & Total \\
\hline Due to randon multipoles & & $\begin{array}{l}1.4 \\
1.0\end{array}$ & $\begin{array}{l}0.8 \\
0.9\end{array}$ & $\begin{array}{l}2.5 \\
2.5\end{array}$ & $\begin{array}{l}0.5 \\
0.6\end{array}$ & 0.1 & $\begin{array}{l}0.2 \\
0.2\end{array}$ & $\begin{array}{l}3.0 \pm 1.4 \\
2.9 \pm 1.3\end{array}$ \\
\hline $\begin{array}{l}\text { Due to feed-down in the } \\
\text { random multipoles }\end{array}$ & $\begin{array}{l}6.7 \\
6.6\end{array}$ & $\begin{array}{l}0.6 \\
0.4\end{array}$ & 0.4 & $\begin{array}{l}1.1 \\
1.1\end{array}$ & $\begin{array}{l}0.5 \\
0.5\end{array}$ & & & $\begin{array}{l}1.4 \\
1.4 \\
1.3\end{array}$ \\
\hline Due to systematic multipoles & & $\begin{array}{l}0.0 \\
0.0\end{array}$ & $\begin{array}{l}1.0 \\
0.5\end{array}$ & $\begin{array}{l}0.1 \\
0.1\end{array}$ & $\begin{array}{l}0.2 \\
0.2\end{array}$ & & & $\frac{1}{0.1}$ \\
\hline $\begin{array}{l}\text { Due to feed-down in the } \\
\text { systenatic multipoles }\end{array}$ & $\begin{array}{l}72.8 \\
72.6\end{array}$ & 0.3 & $\begin{array}{l}0.2 \\
0.4\end{array}$ & $\begin{array}{l}1.1 \\
1.3\end{array}$ & $\begin{array}{l}1.5 \\
1.5\end{array}$ & & & $\begin{array}{l}1.9 \\
2.0\end{array}$ \\
\hline $\begin{array}{l}\text { Due to corrected } \\
\text { systematic multipoles }\end{array}$ & & 0.0 & $\begin{array}{l}0.5 \\
0.3\end{array}$ & $\begin{array}{l}0.0 \\
0.0\end{array}$ & $\begin{array}{l}0.0 \\
0.0\end{array}$ & & & $\begin{array}{l}0.5 \\
0.3\end{array}$ \\
\hline $\begin{array}{l}\text { Due to feed-dowi in the } \\
\text { corr. systematic multipoles }\end{array}$ & $\begin{array}{l}30.5 \\
30.4\end{array}$ & 0.1 & 0.1 & 0.0 & $\begin{array}{l}0.3 \\
0.3\end{array}$ & & & $\begin{array}{l}0.4 \\
0.3\end{array}$ \\
\hline$\Delta \nu\left(10^{-3}\right)$ & $a_{2}^{2}$ & $b_{2}^{2}$ & $b_{3}$ & $a_{3}^{2}$ & $\bar{b}_{3}^{2}$ & & & Total \\
\hline Due to systematic multipoles & $\begin{array}{l}0.0 \\
0.0\end{array}$ & $\begin{array}{l}22.7 \\
31.5\end{array}$ & $\begin{array}{l}-2.3 \\
-2.4\end{array}$ & $\begin{array}{l}0.7 \\
=0.7\end{array}$ & 0.0 & & & $\begin{array}{l}21.0 \\
28.4\end{array}$ \\
\hline $\begin{array}{l}\text { Due to correctied } \\
\text { systematic multipoles }\end{array}$ & $\begin{array}{l}0.0 \\
0.0\end{array}$ & 6.3 & 0.2 & $\begin{array}{l}0.0 \\
0.0\end{array}$ & $\begin{array}{l}0.0 \\
0.0\end{array}$ & & & $\begin{array}{l}6.5 \\
6.1\end{array}$ \\
\hline
\end{tabular}


Table 4: 6 dipoles, 2 TeV, 4 cm magnet aperture.

\begin{tabular}{lcccccccc}
\hline \hline \multicolumn{1}{c}{ Smear (\%) } & $\left(a_{1}\right)$ & $a_{2}$ & $b_{2}$ & $a_{3}$ & $b_{3}$ & $a_{4}$ & $b_{4}$ & Total \\
\hline Due to randon multipoles & & 1.2 & 0.7 & 1.9 & 0.4 & 0.0 & 0.1 & $2.5 \pm 1.1$ \\
& & 0.9 & 0.8 & 2.0 & 0.4 & 0.0 & 0.1 & $2.4 \pm 1.0$ \\
Due to feed-down in the & 6.7 & 0.5 & 0.4 & 0.8 & 0.4 & & & 1.1 \\
random multipoles & 6.6 & 0.3 & 0.5 & 0.3 & 0.4 & & 1.1 \\
Due to systematic multipoles & & 0.0 & 0.5 & 0.1 & 0.1 & & 0.5 \\
& & 0.0 & 0.2 & 0.0 & 0.1 & & 0.3 \\
Due to feed-down in the & 36.4 & 0.2 & 0.2 & 0.5 & 0.7 & & 1.0 \\
systematic multipoles & 36.3 & 0.2 & 0.4 & 0.6 & 0.8 & & 1.1 \\
Due to corrected & & 0.0 & 0.2 & 0.0 & 0.0 & & 0.2 \\
systematic multipoles & & 0.0 & 0.2 & 0.0 & 0.0 & & 0.2 \\
Due to feed-down in the & 15.5 & 0.1 & 0.1 & 0.0 & 0.2 & & 0.2 \\
cori. systematic multipoles & 15.5 & 0.0 & 0.0 & 0.0 & 0.1 & & 0.2 \\
\hline \multicolumn{1}{c}{ Ay $\left(10^{-3}\right)$} & $a_{2}^{2}$ & $b_{2}^{2}$ & $b_{3}$ & $a_{3}^{2}$ & $b_{3}^{2}$ & & Total \\
\hline Due to systematic multipoles & 0.0 & 3.9 & -1.8 & 0.4 & 0.0 & & 2.5 \\
& 0.0 & 4.5 & -1.9 & -0.4 & 0.0 & & 2.2 \\
Due to corrected & 0.0 & 1.1 & 0.1 & 0.0 & 0.0 & & 1.2 \\
systematic multipoles & 0.0 & 1.0 & 0.1 & 0.0 & 0.0 & & 1.1 \\
\hline \hline
\end{tabular}

Toble 5: 6 dipoles, $1 \mathrm{TeV}, 5 \mathrm{~cm}$ magnet aperture.

\begin{tabular}{|c|c|c|c|c|c|c|c|c|}
\hline Snear $(\%)$ & $\left(a_{1}\right)$ & $a_{2}$ & $b_{2}$ & $a_{\mathfrak{3}}$ & $b_{3}$ & $a_{4}$ & $b_{4}$ & Total \\
\hline Due to random multipoles & & $\frac{1.0}{0.7}$ & $\begin{array}{l}0.6 \\
0.6\end{array}$ & $\begin{array}{l}1.5 \\
1.5\end{array}$ & 0.3 & $\begin{array}{l}0.0 \\
0.0\end{array}$ & 0.1 & $\begin{array}{l}1.9 \pm 0.8 \\
1.8 \pm 0.8\end{array}$ \\
\hline $\begin{array}{l}\text { Due to fed-down in the } \\
\text { random mulipoles }\end{array}$ & $\begin{array}{l}\frac{4}{4} .5 \\
4.5 \\
4.5\end{array}$ & $\begin{array}{l}0.3 \\
0.2\end{array}$ & $\begin{array}{l}0.3 \\
0.3\end{array}$ & $\begin{array}{l}0.5 \\
0.6\end{array}$ & $\begin{array}{l}0.3 \\
0.3\end{array}$ & & & $\begin{array}{l}0.7 \\
0.7\end{array}$ \\
\hline Due to systematic multipoles & & $\begin{array}{l}0.0 \\
0.0\end{array}$ & $\begin{array}{l}0.7 \\
0.8\end{array}$ & $\begin{array}{l}0.0 \\
0.0\end{array}$ & 0.1 & & & $\begin{array}{l}0.7 \\
0.4\end{array}$ \\
\hline $\begin{array}{l}\text { Due to feed-down in the } \\
\text { systematic multipoles }\end{array}$ & $\begin{array}{l}47.3 \\
47.2\end{array}$ & 0.1 & 0.1 & $\begin{array}{l}0.6 \\
0.6\end{array}$ & 0.7 & & & $\begin{array}{l}0.9 \\
1.0\end{array}$ \\
\hline $\begin{array}{l}\text { Due to corrected } \\
\text { systematic multipoles }\end{array}$ & & $\begin{array}{l}0.0 \\
0.0\end{array}$ & 0.3 & $\begin{array}{l}0.0 \\
0.0\end{array}$ & $\begin{array}{l}0.0 \\
0.0\end{array}$ & & & 0.3 \\
\hline $\begin{array}{l}\text { Due to feed-down in the } \\
\text { corr. systematic multipoles }\end{array}$ & $\begin{array}{l}19.9 \\
19.9\end{array}$ & $\begin{array}{l}0.1 \\
0.0\end{array}$ & $\begin{array}{l}0.0 \\
0.0\end{array}$ & $\begin{array}{l}0.0 \\
0.0\end{array}$ & 0.2 & & & $\begin{array}{l}0.2 \\
0.1\end{array}$ \\
\hline$\Delta \nu\left(10^{-3}\right)$ & $a_{3}^{2}$ & $\bar{b}_{\frac{2}{2}}^{2}$ & $\bar{t}_{3}$ & $a_{3}^{2}$ & $b_{3}^{2}$ & & & Total \\
\hline Dne to systematic multipoles & $\begin{array}{l}0.0 \\
0.0\end{array}$ & $\begin{array}{l}9.0 \\
11.4\end{array}$ & $\begin{array}{l}-1.2 \\
-1.2\end{array}$ & $\begin{array}{r}0.2 \\
-0.2\end{array}$ & $\begin{array}{l}0.0 \\
0.0\end{array}$ & & & $\begin{array}{l}8.1 \\
10.0\end{array}$ \\
\hline $\begin{array}{l}\text { Due to corrected } \\
\text { systematic multipoles }\end{array}$ & 0.0 & $\begin{array}{l}2.5 \\
2.3\end{array}$ & $\begin{array}{l}0.1 \\
0.1\end{array}$ & $\begin{array}{l}0.0 \\
0.0\end{array}$ & $\begin{array}{l}0.0 \\
0.0\end{array}$ & & & $\begin{array}{l}2.6 \\
2.4\end{array}$ \\
\hline
\end{tabular}


Table 4: $\bar{b}$ dipoles, 2 TeV, 4 cm magnet aperture

\begin{tabular}{|c|c|c|c|c|c|c|c|c|}
\hline Smear $(\%)$ & $\left(a_{1}\right)$ & $\sigma_{2}$ & $b_{3}$ & $a_{3}$ & $b_{3}$ & $a_{\underline{\underline{\underline{4}}}}$ & $b_{4}$ & Total \\
\hline Due to random multipoles & & $\begin{array}{l}1.2 \\
0.9\end{array}$ & $\begin{array}{l}0.7 \\
0.8\end{array}$ & $\begin{array}{l}1.9 \\
2.0\end{array}$ & $\begin{array}{l}0.4 \\
0.4\end{array}$ & $\begin{array}{l}0.0 \\
0.0\end{array}$ & 0.1 & $\begin{array}{l}2.5 \pm 1.1 \\
2.4 \pm 1.0\end{array}$ \\
\hline $\begin{array}{l}\text { Due to feed-down in the } \\
\text { random multipoles }\end{array}$ & $\begin{array}{l}6.7 \\
6.6\end{array}$ & 0.5 & $\begin{array}{l}0.4 \\
0.5\end{array}$ & $\begin{array}{l}0.8 \\
0.9\end{array}$ & $\begin{array}{l}0.4 \\
0.4\end{array}$ & & & $\frac{1.1}{1.1}$ \\
\hline Die to systerratic multipoles & & 0.0 & 0.5 & 0.1 & 0.1 & & & 0.5 \\
\hline $\begin{array}{l}\text { Dite to feed-down in the } \\
\text { systematic multipoles }\end{array}$ & $\begin{array}{l}36.4 \\
36.3\end{array}$ & $\begin{array}{l}0.2 \\
0.2\end{array}$ & $\begin{array}{l}0.2 \\
0.4\end{array}$ & $\begin{array}{l}0.5 \\
0.6\end{array}$ & $\begin{array}{l}0.7 \\
0.8\end{array}$ & & & $\begin{array}{l}1.0 \\
1.1\end{array}$ \\
\hline $\begin{array}{l}\text { Due to corrected } \\
\text { systematic multipoles }\end{array}$ & & 0.0 & $\begin{array}{l}0.2 \\
0.2\end{array}$ & 0.0 & 0.0 & & & $\begin{array}{l}0 . \overline{2} \\
0.2\end{array}$ \\
\hline $\begin{array}{l}\text { Dise to feed-down in the } \\
\text { corr. systematic multipoles }\end{array}$ & $\begin{array}{l}15.5 \\
15.5\end{array}$ & 0.1 & 0.1 & $\begin{array}{l}0.0 \\
0.0\end{array}$ & 0.2 & & & $\begin{array}{l}0.2 \\
0.2\end{array}$ \\
\hline$\Delta v\left(10^{-3}\right)$ & $a_{2}^{2}$ & $3 \frac{2}{2}$ & $\bar{b}_{3}$ & $a_{3}^{2}$ & $\frac{i 2}{3}$ & & & Total \\
\hline Due to systematic multipoles & 0.0 & $\begin{array}{l}3.9 \\
3.9 \\
4.50\end{array}$ & $\begin{array}{l}-1.8 \\
-1.9\end{array}$ & $\begin{array}{l}0.4 \\
-0.4\end{array}$ & $\begin{array}{l}0.0 \\
0.0\end{array}$ & & & $\begin{array}{l}2.5 \\
2.2\end{array}$ \\
\hline $\begin{array}{l}\text { Due to corrected } \\
\text { systematic multipoles }\end{array}$ & $\begin{array}{l}0.0 \\
0.0\end{array}$ & $\frac{1}{1.0}$ & 0.1 & $\begin{array}{l}0.0 \\
0.0\end{array}$ & $\begin{array}{l}0.0 \\
0.0\end{array}$ & & & $\begin{array}{l}1.2 \\
1.1\end{array}$ \\
\hline
\end{tabular}

Table 5: 6 dipoles, $1 \mathrm{TeV}, 5 \mathrm{~cm}$ magnet aperbure.

\begin{tabular}{|c|c|c|c|c|c|c|c|c|}
\hline Smear $(\%)$ & $\left(a_{1}\right)$ & $a_{2}$ & $\overline{\bar{b}_{\overline{2}}}$ & $a s$ & $\bar{b}_{3}$ & $a_{4}$ & $b_{4}$ & Totai \\
\hline Due to random multipoles & & $\frac{1.0}{0.7}$ & 0.6 & $\frac{1.5}{1.5}$ & $0 . \overline{3}$ & 0.0 & $\begin{array}{l}0.1 \\
0.1\end{array}$ & $\begin{array}{l}1.9 \pm 0.8 \\
1.8 \pm 0.8\end{array}$ \\
\hline $\begin{array}{l}\text { Due to feed-down in the } \\
\text { random multipoles }\end{array}$ & $\begin{array}{l}4.5 \\
4.5\end{array}$ & $0 . \hat{3}$ & 0.3 & $\begin{array}{l}0.5 \\
0.6\end{array}$ & $\begin{array}{l}0.3 \\
0.3\end{array}$ & & & $\begin{array}{l}0.7 \\
0.7\end{array}$ \\
\hline Due to systematic multipoles & & 0.0 & $\begin{array}{l}0.7 \\
0.3\end{array}$ & $\begin{array}{l}0.0 \\
0.0\end{array}$ & 0.1 & & & $\begin{array}{l}0.7 \\
0.4\end{array}$ \\
\hline $\begin{array}{l}\text { Due to feed-down in the } \\
\text { systematic multipoles }\end{array}$ & $\begin{array}{l}47.3 \\
47.2\end{array}$ & 0.1 & 0.1 & $\begin{array}{l}0.5 \\
0.6\end{array}$ & 0.7 & & & $\begin{array}{l}0.9 \\
1.0\end{array}$ \\
\hline $\begin{array}{l}\text { Due to corrected } \\
\text { systematic multipoles }\end{array}$ & & 0.0 & 0.3 & $\begin{array}{l}0.0 \\
0.0\end{array}$ & $\begin{array}{l}0.0 \\
0.0\end{array}$ & & & $\begin{array}{l}0.3 \\
0.2\end{array}$ \\
\hline $\begin{array}{l}\text { Due to feed-down in the } \\
\text { cort. systematic multipoles }\end{array}$ & $\begin{array}{l}19.9 \\
19.9\end{array}$ & 0.1 & 0.0 & $\begin{array}{l}0.0 \\
0.0\end{array}$ & $\begin{array}{l}0.2 \\
0.1 \\
\end{array}$ & & & 0.2 \\
\hline$\Delta \nu\left(10^{-3}\right)$ & $a_{2}^{2}$ & $b_{2}^{2}$ & $b_{3}$ & $a_{5}^{2}$ & $b_{3}^{2}$ & & & Total \\
\hline Due to systematic multipoles & 0.0 & $\begin{array}{l}9.0 \\
11.4\end{array}$ & $\begin{array}{l}-1.2 \\
=1.2\end{array}$ & $\begin{array}{l}0.2 \\
0.2\end{array}$ & $\begin{array}{l}0.0 \\
0.0\end{array}$ & & & $\begin{array}{l}8.1 \\
10.0\end{array}$ \\
\hline $\begin{array}{l}\text { Due to corrected } \\
\text { systematic mulipoles }\end{array}$ & 0.0 & 2.5 & 0.1 & $\begin{array}{l}0.0 \\
0.0\end{array}$ & $\begin{array}{l}0.0 \\
0.0\end{array}$ & & & $\begin{array}{l}2.6 \\
2.4\end{array}$ \\
\hline
\end{tabular}


Table $8: 5$ dipoles, $2 \mathrm{TeV}, 4$ cm magnet aperture.

\begin{tabular}{|c|c|c|c|c|c|c|c|c|}
\hline Smear $(\%)$ & $\left(a_{1}\right)$ & $a_{2}$ & $b_{2}$ & $a_{3}$ & $\bar{v}_{3}$ & $a_{4}$ & $\bar{b}_{4}$ & Total \\
\hline Due to randon miltipoles & & $\begin{array}{l}1.0 \\
0.7\end{array}$ & $\begin{array}{l}0.6 \\
0.7\end{array}$ & $\begin{array}{l}1.5 \\
1.5\end{array}$ & $\begin{array}{l}0.3 \\
0.3\end{array}$ & $\begin{array}{l}0.0 \\
0.0\end{array}$ & 0.1 & $\begin{array}{l}1.9 \pm 0.9 \\
1.9 \pm 0.8\end{array}$ \\
\hline $\begin{array}{l}\text { Due to feed-down in the } \\
\text { random multipoles }\end{array}$ & $\begin{array}{l}5.8 \\
5.7\end{array}$ & $\begin{array}{l}0.4 \\
0.3\end{array}$ & $\begin{array}{l}0.3 \\
0.4\end{array}$ & 0.7 & 0.3 & & & 0.9 \\
\hline Due to systematic multipoles & & $\begin{array}{l}0.0 \\
0.0\end{array}$ & $\begin{array}{l}0.4 \\
0.2\end{array}$ & $\begin{array}{l}0.0 \\
0.0\end{array}$ & $\begin{array}{l}0.1 \\
0.1\end{array}$ & & & $\begin{array}{l}0.4 \\
0.2\end{array}$ \\
\hline $\begin{array}{l}\text { Due to feed-down in the } \\
\text { systematic multipoles }\end{array}$ & $\begin{array}{l}32.1 \\
32.1\end{array}$ & $\begin{array}{l}0.2 \\
0.1\end{array}$ & $\begin{array}{l}0.1 \\
0.3\end{array}$ & $\begin{array}{l}0.4 \\
0.4\end{array}$ & $\begin{array}{l}0.5 \\
0.5\end{array}$ & & & $\begin{array}{l}0.7 \\
0.8\end{array}$ \\
\hline $\begin{array}{l}\text { Due to corrected } \\
\text { systematic multipoles }\end{array}$ & & $\begin{array}{l}0.0 \\
0.0\end{array}$ & $\begin{array}{l}0.2 \\
0.2\end{array}$ & 0.0 & $\begin{array}{l}0.0 \\
0.0\end{array}$ & & & 0.2 \\
\hline $\begin{array}{l}\text { Due to feed-down in the } \\
\text { corr. systematic multipoles }\end{array}$ & $\begin{array}{l}14.6 \\
14.6\end{array}$ & $\begin{array}{l}0.1 \\
0.0\end{array}$ & 0.1 & $\begin{array}{l}0.0 \\
0.0\end{array}$ & 0.1 & & & 0.1 \\
\hline$\Delta \nu\left(10^{-5}\right)$ & $a_{2}^{\overline{2}}$ & $b_{\frac{2}{2}}^{2}$ & $b_{3}$ & $a_{3}^{2}$ & $3_{3}^{2}$ & & & Total \\
\hline Due to systematic multipoles & 0.0 & $\begin{array}{l}2.1 \\
1.4\end{array}$ & $\begin{array}{l}-1.5 \\
-1.5\end{array}$ & $\begin{array}{c}0.2 \\
-0.3\end{array}$ & $\begin{array}{l}0.0 \\
0.0\end{array}$ & & & $\begin{array}{l}0.8 \\
=0.4\end{array}$ \\
\hline $\begin{array}{l}\text { Due to corrected } \\
\text { systematic multipoles }\end{array}$ & $\begin{array}{l}0.0 \\
0.0\end{array}$ & 0.5 & 0.1 & $\begin{array}{l}0.0 \\
0.0\end{array}$ & $\begin{array}{l}0.0 \\
0.0\end{array}$ & & & $\begin{array}{l}0 . \overline{7} \\
0.6\end{array}$ \\
\hline
\end{tabular}

Table 9: 5 dipoles, 1 TeV, 5 cm magnet aperture

\begin{tabular}{|c|c|c|c|c|c|c|c|c|}
\hline Smear $(\%)$ & $\left(a_{1}\right)$ & $a_{2}$ & $b_{2}$ & $a_{3}$ & $b_{3}$ & $a_{4}$ & $b_{A_{n}}$ & Total \\
\hline Due to random multipoles & & $\begin{array}{l}0.8 \\
0.6\end{array}$ & $\begin{array}{l}0.4 \\
0.5 \\
0.5\end{array}$ & $\begin{array}{l}1.1 \\
1.1\end{array}$ & $\begin{array}{l}0.2 \\
0.3\end{array}$ & $\begin{array}{l}0.0 \\
0.0\end{array}$ & 0.1 & $\begin{array}{l}1.4 \pm 0.8 \\
1.4 \pm 0.6\end{array}$ \\
\hline $\begin{array}{l}\text { Due to feed-down in the } \\
\text { random multipoles }\end{array}$ & $\begin{array}{l}3.9 \\
3.9\end{array}$ & $\begin{array}{l}0.3 \\
0.2\end{array}$ & $\begin{array}{l}0.2 \\
0.3\end{array}$ & $\begin{array}{l}0.4 \\
0.4\end{array}$ & $\begin{array}{l}0.2 \\
0.2\end{array}$ & & & $\begin{array}{l}0.6 \\
0.6\end{array}$ \\
\hline Due to systematic multipoles & & $\begin{array}{l}0.0 \\
0.0\end{array}$ & $\begin{array}{l}0.5 \\
0.3\end{array}$ & $\begin{array}{l}0.0 \\
0.0\end{array}$ & 0.1 & & & $\begin{array}{l}0.5 \\
0.3\end{array}$ \\
\hline $\begin{array}{l}\text { Due to feed-down in the } \\
\text { systematic multipoles }\end{array}$ & $\begin{array}{l}1100 \\
40.0 \\
40.0\end{array}$ & 0.1 & 0.1 & $\begin{array}{l}0.3 \\
0.4\end{array}$ & $0 . \overline{3}$ & & & $\begin{array}{l}0.6 \\
0.7\end{array}$ \\
\hline $\begin{array}{l}\text { Due to corrected } \\
\text { systematic multipoles }\end{array}$ & & $\begin{array}{l}0.0 \\
0.0\end{array}$ & $\begin{array}{l}0.3 \\
0.2\end{array}$ & $\begin{array}{l}0.0 \\
0.0\end{array}$ & 0.0 & & & 0.3 \\
\hline $\begin{array}{l}\text { Due to feed-down in the } \\
\text { corr. systematic multipoles }\end{array}$ & $\begin{array}{l}17.5 \\
17.5 \\
\end{array}$ & 0.0 & $\begin{array}{l}0.0 \\
0.0\end{array}$ & $\begin{array}{l}0.0 \\
0.0 \\
\end{array}$ & 0.1 & & & $\begin{array}{l}0.1 \\
0.1\end{array}$ \\
\hline$\Delta i\left(10^{-3}\right)$ & $a_{2}^{2}$ & $b_{2}^{2}$ & $b_{3}$ & $a_{3}^{2}$ & $\frac{2}{3}$ & & & Totail \\
\hline Due to systematic multipoles & 0.0 & $\begin{array}{l}4.8 \\
4.5 \\
4.5\end{array}$ & $\begin{array}{l}-0.9 \\
-1.0\end{array}$ & $\begin{array}{l}0.1 \\
-0.1\end{array}$ & 0.0 & & & $\begin{array}{l}3.9 \\
3.4\end{array}$ \\
\hline $\begin{array}{l}\text { Due to corrected } \\
\text { systematic multipoles }\end{array}$ & $\begin{array}{l}0.0 \\
0.0\end{array}$ & $\frac{1.3}{1.2}$ & $\begin{array}{l}0.1 \\
0.1\end{array}$ & $\begin{array}{l}0.0 \\
0.0\end{array}$ & $\begin{array}{l}0.0 \\
0.0\end{array}$ & & & $\begin{array}{l}1.4 \\
1.3\end{array}$ \\
\hline
\end{tabular}


Teble 10: 5 dipoles, 2 TeV, 5 cri magnet aperture.

\begin{tabular}{|c|c|c|c|c|c|c|c|c|}
\hline Smear $(\%)$ & $\left(a_{1}\right)$ & $a_{2}$ & $b_{2}$ & $a_{3}$ & $b_{3}$ & $\hat{\theta}_{\hat{\mathbf{a}}}$ & $\dot{b}_{4}$ & Total \\
\hline Due to random multipoles & & 0.7 & 0.4 & 0.9 & 0.2 & 0.0 & $\begin{array}{l}0.0 \\
0.1\end{array}$ & $\frac{1}{1.2}+\frac{2}{1.1 \pm 0.5}$ \\
\hline $\begin{array}{l}\text { Due to feed-down in the } \\
\text { random mutipoles }\end{array}$ & $\begin{array}{l}3.9 \\
3.9\end{array}$ & $\begin{array}{l}0.2 \\
0.2\end{array}$ & $\begin{array}{l}0.2 \\
0.2\end{array}$ & 0.3 & $\begin{array}{l}0.2 \\
0.2\end{array}$ & & & $\begin{array}{l}0.5 \\
0.5\end{array}$ \\
\hline Due to systematic multipoles & & $\begin{array}{l}0.0 \\
0.0\end{array}$ & $\begin{array}{l}0.3 \\
0.2\end{array}$ & $\begin{array}{l}0.0 \\
0.0\end{array}$ & 0.1 & & & $\begin{array}{l}0.3 \\
0.2\end{array}$ \\
\hline $\begin{array}{l}\text { Due to feed-down in the } \\
\text { systematic multipoles }\end{array}$ & $\begin{array}{l}22.6 \\
22.6\end{array}$ & 0.1 & 0.1 & $\begin{array}{l}0.1 \\
0.2\end{array}$ & $\begin{array}{l}0.2 \\
0.2\end{array}$ & & & 0.3 \\
\hline $\begin{array}{l}\text { Due to corrected } \\
\text { systematic multipoles }\end{array}$ & & $\begin{array}{l}0.0 \\
0.0\end{array}$ & 0.2 & $\begin{array}{l}0.0 \\
0.0\end{array}$ & 0.0 & & & 0.2 \\
\hline $\begin{array}{l}\text { Due to feed-down in the } \\
\text { corr. systematic multipoles }\end{array}$ & $\begin{array}{l}7.8 \\
7.8 \\
\end{array}$ & 0.0 & 0.0 & 0.0 & 0.0 & & & 0.1 \\
\hline$\Delta v\left(10^{-3}\right)$ & $a_{2}^{2}$ & $b \frac{2}{2}$ & $b_{\bar{s}}$ & $a_{3}^{2}$ & $b_{3}^{2}$ & & & Total \\
\hline Due to systematic multipoles & 0.0 & 0.7 & $\begin{array}{l}-0.8 \\
-0.8\end{array}$ & 0.0 & $\begin{array}{l}0.0 \\
0.0\end{array}$ & & & $\begin{array}{r}0.0 \\
-0.8\end{array}$ \\
\hline $\begin{array}{l}\text { Due to corrected } \\
\text { systematic multipoles }\end{array}$ & $\begin{array}{l}0.0 \\
0.0\end{array}$ & $\begin{array}{c}-0.3 \\
0.2\end{array}$ & $\begin{array}{l}0.1 \\
0.1\end{array}$ & $\begin{array}{l}0.0 \\
0.0\end{array}$ & 0.0 & & & $\begin{array}{c}-0.3 \\
0.3\end{array}$ \\
\hline
\end{tabular}

Table 11: 4 dipoles, $1 \mathrm{TeV}, 4$ cm magnet aperture.

\begin{tabular}{|c|c|c|c|c|c|c|c|c|}
\hline Smear $(\%)$ & $\left(a_{1}\right)$ & $a_{2}$ & $b_{2}$ & $\bar{z}_{3}$ & $\varepsilon_{3}$ & $a_{4}$ & $b_{4}$ & Total \\
\hline Due to random multipoles & & 0.9 & 0.5 & $\begin{array}{l}1.4 \\
1.4\end{array}$ & 0.3 & 0.0 & $\begin{array}{l}0.1 \\
0.1\end{array}$ & $\begin{array}{l}1.8 \div 0.8 \\
1.7 \pm 0.7\end{array}$ \\
\hline $\begin{array}{l}\text { Due to feed-down in the } \\
\text { random multipoles }\end{array}$ & $\begin{array}{l}4.9 \\
4.9\end{array}$ & $\begin{array}{l}0.4 \\
0.2\end{array}$ & $\begin{array}{l}0.3 \\
0.4\end{array}$ & 0.6 & 0.3 & & & $\begin{array}{l}0.8 \\
0.8\end{array}$ \\
\hline Due to systeñatic multipoles & & $\begin{array}{l}0.0 \\
0.0\end{array}$ & $\begin{array}{l}0.5 \\
0.3\end{array}$ & $\begin{array}{l}0.0 \\
0.0\end{array}$ & 0.1 & & & $\begin{array}{l}0 . \overline{3} \\
0.3\end{array}$ \\
\hline $\begin{array}{l}\text { Due to feed-down in the } \\
\text { systematic multipoles }\end{array}$ & $\begin{array}{l}52.2 \\
52.1\end{array}$ & $\begin{array}{l}0.1 \\
0.1\end{array}$ & $\begin{array}{l}0.1 \\
0.2\end{array}$ & $\begin{array}{l}0.5 \\
0.5\end{array}$ & 0.7 & & & 0.9 \\
\hline $\begin{array}{l}\text { Due to corrected } \\
\text { systematic multipoles }\end{array}$ & & $\begin{array}{l}0.0 \\
0.0\end{array}$ & $\begin{array}{l}0.3 \\
0.3\end{array}$ & $\begin{array}{l}0.0 \\
0.0\end{array}$ & 0.0 & & & 0.3 \\
\hline $\begin{array}{l}\text { Due to feed-down in the } \\
\text { cort, systematic multipoles }\end{array}$ & $\begin{array}{l}23.0 \\
23.0\end{array}$ & 0.1 & $\begin{array}{l}0.0 \\
0.0\end{array}$ & $\begin{array}{l}0.0 \\
0.0\end{array}$ & $\begin{array}{l}0.2 \\
0.1\end{array}$ & & & 0.2 \\
\hline$\Delta v\left(10^{-3}\right)$ & $a_{2}^{2}$ & $b_{p}^{2}$ & $b_{3}$ & $a_{3}^{2}$ & $b_{3}^{2}$ & & & Total \\
\hline Due to systematic multipoles & $\begin{array}{l}0.0 \\
0.0\end{array}$ & $\begin{array}{l}6.2 \\
4.3\end{array}$ & $\begin{array}{l}-1.6 \\
-1.6\end{array}$ & $\begin{array}{c}0.2 \\
-0.2\end{array}$ & $\begin{array}{l}0.0 \\
0.0\end{array}$ & & & $\frac{4.9}{2.5}$ \\
\hline $\begin{array}{l}\text { Due to corrected } \\
\text { systematic multipoles }\end{array}$ & $\begin{array}{l}0.0 \\
0.0\end{array}$ & $\begin{array}{l}1.8 \\
1.8\end{array}$ & $\begin{array}{l}0.1 \\
0.1\end{array}$ & 0.0 & $\begin{array}{l}0.0 \\
0.0\end{array}$ & & & $\frac{1.9}{1.6}$ \\
\hline
\end{tabular}


Tabie 12: 4 dipoles, $2 \mathrm{TeV}$, 4 cm magnet aporture.

\begin{tabular}{|c|c|c|c|c|c|c|c|c|}
\hline Smear (\%) & $\left(a_{1}\right)$ & $a_{2}$ & $\bar{b}_{2}$ & 63 & $b_{3}$ & $a_{\frac{4}{4}}$ & $b_{A}$ & Total \\
\hline Due to random multipoles & & 0.8 & $\begin{array}{l}0.5 \\
0.5\end{array}$ & 1.1 & $\begin{array}{l}0.2 \\
0.3\end{array}$ & $\begin{array}{l}0.0 \\
0.0\end{array}$ & $\begin{array}{l}0.1 \\
0.1\end{array}$ & $\begin{array}{l}1.5+0.6 \\
1.4+0.6\end{array}$ \\
\hline $\begin{array}{l}\text { Due to feed-down in the } \\
\text { random multipoles }\end{array}$ & $\begin{array}{l}4.9 \\
4.9\end{array}$ & 0.3 & 0.3 & 0.5 & 0.2 & & & $\begin{array}{l}0.7 \\
0.7\end{array}$ \\
\hline Due to systematic multipoles & & $\begin{array}{l}0.0 \\
0.0\end{array}$ & $\begin{array}{l}0 . \overline{3} \\
0.2\end{array}$ & $\begin{array}{l}0.0 \\
0.0\end{array}$ & $\begin{array}{l}0.1 \\
0.1\end{array}$ & & & $\begin{array}{l}0.3 \\
0.2\end{array}$ \\
\hline $\begin{array}{l}\text { Due to feed down in the } \\
\text { systematic multipoles }\end{array}$ & $\begin{array}{l}30.2 \\
30.1\end{array}$ & 0.1 & $\begin{array}{l}0.1 \\
0.2\end{array}$ & $\begin{array}{l}0.2 \\
0.3\end{array}$ & $\begin{array}{l}0.4 \\
0.4\end{array}$ & & & $\begin{array}{l}0.5 \\
0.5\end{array}$ \\
\hline $\begin{array}{l}\text { Due to corrected } \\
\text { systematio multipoles }\end{array}$ & & 0.0 & $\begin{array}{l}0.2 \\
0.2\end{array}$ & 0.0 & $\begin{array}{l}0.0 \\
0.0\end{array}$ & & & $\begin{array}{l}0.2 \\
0.2\end{array}$ \\
\hline $\begin{array}{l}\text { Due to feed down in the } \\
\text { corr. systemabic multipoles }\end{array}$ & $\begin{array}{l}17.7 \\
17.7\end{array}$ & 0.1 & $\begin{array}{l}0.0 \\
0.0\end{array}$ & $\begin{array}{l}0.0 \\
0.0\end{array}$ & 0.1 & & & 0.1 \\
\hline$\Delta=\left(10^{-3}\right)$ & $\overline{6}^{\frac{2}{2}}$ & $\xi_{2}^{2}$ & $\dot{b}_{3}$ & $a_{3}^{2}$ & $i_{3}^{2}$ & & & Total \\
\hline Diue to systematic multipoles & $\begin{array}{l}0.0 \\
0.0\end{array}$ & $\begin{array}{l}0.8 \\
-0.6\end{array}$ & $\begin{array}{l}-1.3 \\
-1.3\end{array}$ & $\begin{array}{r}0.1 \\
=0.1\end{array}$ & 0.0 & & & $\begin{array}{l}-0.3 \\
=2.0\end{array}$ \\
\hline $\begin{array}{l}\text { Dive to corrected } \\
\text { systematic multipoles }\end{array}$ & $\begin{array}{l}0.0 \\
0.0\end{array}$ & 0.1 & $\begin{array}{l}0.1 \\
0.1\end{array}$ & 0.0 & 0.0 & & & $\begin{array}{l}0.2 \\
0.2\end{array}$ \\
\hline
\end{tabular}

Tôle 19: 4 dipoles, $1 \mathrm{TeV}_{\mathrm{j}} 5$ cm magnet aperiure.

\begin{tabular}{|c|c|c|c|c|c|c|c|c|}
\hline $\operatorname{sincas}(\%)$ & $\left(a_{1}\right)$ & $\sigma_{2}$ & $b_{2}$ & $a_{3}$ & $\xi_{3}$ & $a_{\frac{1}{3}}$ & $b_{4}$ & Total \\
\hline Due to random multipoles & & $\begin{array}{l}0.6 \\
0.4\end{array}$ & $\begin{array}{l}0.4 \\
0.4\end{array}$ & $\begin{array}{l}0.8 \\
0.8\end{array}$ & $\begin{array}{l}0.2 \\
0.2\end{array}$ & $\begin{array}{l}0.0 \\
0.0\end{array}$ & $\begin{array}{l}0.0 \\
0.1\end{array}$ & $\begin{array}{l}1.1 \pm 0.5 \\
1.0 \pm 0.4\end{array}$ \\
\hline $\begin{array}{l}\text { Due to feed-domn in the } \\
\text { random multipoles }\end{array}$ & $\begin{array}{l}3.4 \\
3.4\end{array}$ & 0.2 & 0.2 & 0.3 & $\begin{array}{l}0.2 \\
0.2\end{array}$ & & & 0.4 \\
\hline Due to systematic multipoles & & $\begin{array}{l}0.0 \\
0.0\end{array}$ & $\begin{array}{l}0.4 \\
0.3\end{array}$ & $\begin{array}{l}0.0 \\
0.0\end{array}$ & 0.1 & & & $\begin{array}{l}0.4 \\
0.3\end{array}$ \\
\hline $\begin{array}{l}\text { Due to feed-down in the } \\
\text { systematic multipoles }\end{array}$ & $\begin{array}{l}36.5 \\
36.5\end{array}$ & $\begin{array}{l}0 . \overline{1} \\
0 . \overline{1}\end{array}$ & 0.1 & $\begin{array}{l}0.2 \\
0.2\end{array}$ & 0.3 & & & $0 . \frac{4}{3}$ \\
\hline $\begin{array}{l}\text { Due to corrected } \\
\text { systematic multipoles }\end{array}$ & & 0.0 & $\begin{array}{l}0.2 \\
0.2\end{array}$ & $\begin{array}{l}0.0 \\
0.0\end{array}$ & 0.0 & & & 0.2 \\
\hline $\begin{array}{l}\text { Due to feed-down in the } \\
\text { corr. systematic mulipoles }\end{array}$ & $\begin{array}{l}19.0 \\
19.0\end{array}$ & 0.0 & 0.0 & 0.0 & 0.1 & & & $\begin{array}{l}0.1 \\
0.1\end{array}$ \\
\hline$\Delta \nu\left(10^{-3}\right)$ & $a_{\hat{2}}^{2}$ & $b_{2}^{2}$ & $\bar{b}_{3}$ & $a_{3}^{\hat{z}}$ & $b_{3}^{2}$ & & & Totbal \\
\hline Due to systematic multipoles & 0.0 & $\begin{array}{l}2.2 \\
0.1\end{array}$ & $\begin{array}{l}-0.8 \\
-0.8\end{array}$ & $\begin{array}{r}0.1 \\
-0.1\end{array}$ & $\begin{array}{l}0.0 \\
0.0\end{array}$ & & & $\begin{array}{r}1.5 \\
-0.7\end{array}$ \\
\hline $\begin{array}{l}\text { Due to corrected } \\
\text { systematic nultipoles }\end{array}$ & $\begin{array}{l}0.0 \\
0.0\end{array}$ & $\begin{array}{l}0 . \overline{5} \\
0 . \bar{\pi}\end{array}$ & 0.1 & $\begin{array}{l}0.0 \\
0.0\end{array}$ & $\begin{array}{l}0.0 \\
0.0\end{array}$ & & & 0.6 \\
\hline
\end{tabular}


Table 14: 4 dipoles, $2 \mathrm{TeV}, 5 \mathrm{~cm}$ magnet aperture.

\begin{tabular}{|c|c|c|c|c|c|c|c|c|}
\hline Smear $(\%)$ & $\left(a_{1}\right)$ & $a_{\overline{2}}$ & $\bar{\delta}_{\overline{2}}$ & $a_{3}$ & $b_{3}$ & $a_{4}$ & $\bar{b}_{a}$ & Total \\
\hline Due to random multipoles & & $\begin{array}{l}0.6 \\
0.4\end{array}$ & 0.3 & 0.7 & 0.1 & $\begin{array}{l}0.0 \\
0.0\end{array}$ & $\begin{array}{l}0.0 \\
0.0\end{array}$ & $\begin{array}{l}0.9 \pm 0.4 \\
0.9 \pm 0.4\end{array}$ \\
\hline $\begin{array}{l}\text { Due to feed-down in the } \\
\text { random multipoles }\end{array}$ & $\begin{array}{l}3.4 \\
3.4\end{array}$ & $\begin{array}{l}0.2 \\
0.1\end{array}$ & 0.2 & 0.2 & 0.1 & & & $\begin{array}{l}0 . \frac{4}{4} \\
0 . \underline{4}\end{array}$ \\
\hline Due to systematic multipoles & & 0.0 & $\begin{array}{l}0.4 \\
0.2\end{array}$ & $\begin{array}{l}0.0 \\
0.0\end{array}$ & 0.0 & & & $\begin{array}{l}0.4 \\
0.2\end{array}$ \\
\hline $\begin{array}{l}\text { Due to feed-down in the } \\
\text { systematic multipoles }\end{array}$ & $\begin{array}{l}39.6 \\
39.5\end{array}$ & $\begin{array}{l}0.0 \\
0.0\end{array}$ & $\begin{array}{l}0.0 \\
0.1\end{array}$ & $\begin{array}{l}0.1 \\
0.1\end{array}$ & $\begin{array}{l}0.1 \\
0.2\end{array}$ & & & $\begin{array}{l}0.2 \\
0.2\end{array}$ \\
\hline $\begin{array}{l}\text { Due to corrected } \\
\text { systematic multipoles }\end{array}$ & & $\begin{array}{l}0.0 \\
0.0\end{array}$ & $\begin{array}{l}0.2 \\
0.2\end{array}$ & 0.0 & $\begin{array}{l}0.0 \\
0.0\end{array}$ & & & $\begin{array}{l}0.2 \\
0.2\end{array}$ \\
\hline $\begin{array}{l}\text { Due to feed-down in the } \\
\text { corr, systematic multipoles }\end{array}$ & $\begin{array}{l}16.8 \\
16.8\end{array}$ & $\begin{array}{l}0.0 \\
0.0\end{array}$ & $\begin{array}{l}0.0 \\
0.0\end{array}$ & $\begin{array}{l}0.0 \\
0.0\end{array}$ & 0.0 & & & $\begin{array}{l}0.0 \\
0.0\end{array}$ \\
\hline$\Delta y\left(10^{-3}\right)$ & $a_{2}^{\frac{2}{2}}$ & $b_{\frac{2}{2}}^{2}$ & $b_{3}$ & $a_{3}^{2}$ & $b_{\overline{3}}^{2}$ & & & Total \\
\hline Due to systematic multipoles & 0.0 & $\begin{array}{l}0.4 \\
2.8\end{array}$ & $\begin{array}{l}-0.6 \\
-0.6\end{array}$ & $\begin{array}{l}0.0 \\
0.0\end{array}$ & 0.0 & & & $\begin{array}{l}-0.2 \\
2.3\end{array}$ \\
\hline $\begin{array}{l}\text { Due to corrected } \\
\text { systematic multipoles }\end{array}$ & 0.0 & $\begin{array}{l}-0.1 \\
-0.1\end{array}$ & $\begin{array}{l}0.1 \\
0.1\end{array}$ & 0.0 & $\begin{array}{l}0.0 \\
0.0\end{array}$ & & & $\begin{array}{l}-0.1 \\
-0.1\end{array}$ \\
\hline
\end{tabular}

\subsection{SMAAR VERSUS TUNE}

The analytical expressions for the smear may be used to study the dependence on the working point. Since the main contribution is from the random multipoles, only these will be considered without feed-down. Figure 1 to 6 shows contour plots of $\max \left(S_{x}, S_{y}\right)$ for the cases of $4 \mathrm{~cm}$ magnet aperture from Table 1 . The contour plots were obtained by calculating smear values for a $100 \times 100$ grid and using TOPDR,AWER. [20] Since the smear goes to infinity on the resonances, the values above $100 \%$ were cut. The wiggling of the contour lines close to the resonances is due to the interpolation between grid points.

It is clear from the plots that if only smear is considered a more favorable working point than the normal

$$
\nu_{x}=81.285, \quad \nu_{y}=82.265
$$

would be, e.g., 


$$
v_{x}=81.38, \quad v_{y}=82.44
$$

for the 6 dipoles case.

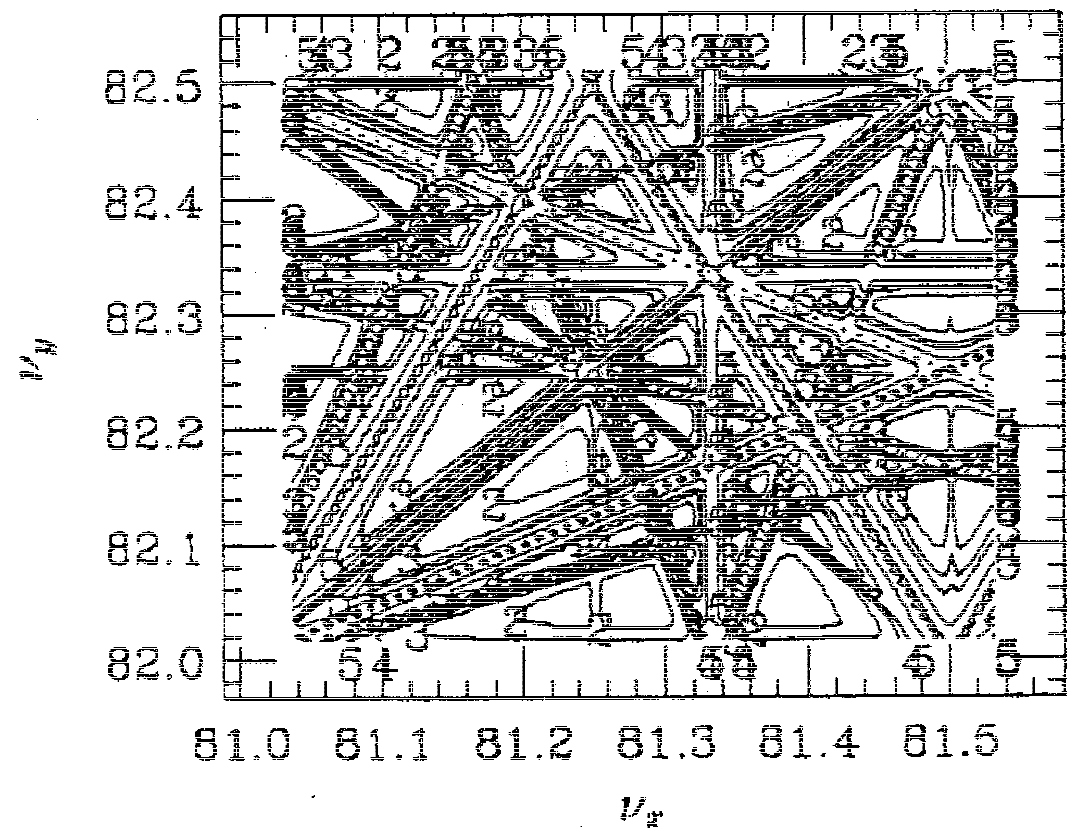

Figure $1: 6$ dipoles, $1 \mathrm{TeV}, 4 \mathrm{~cm}$

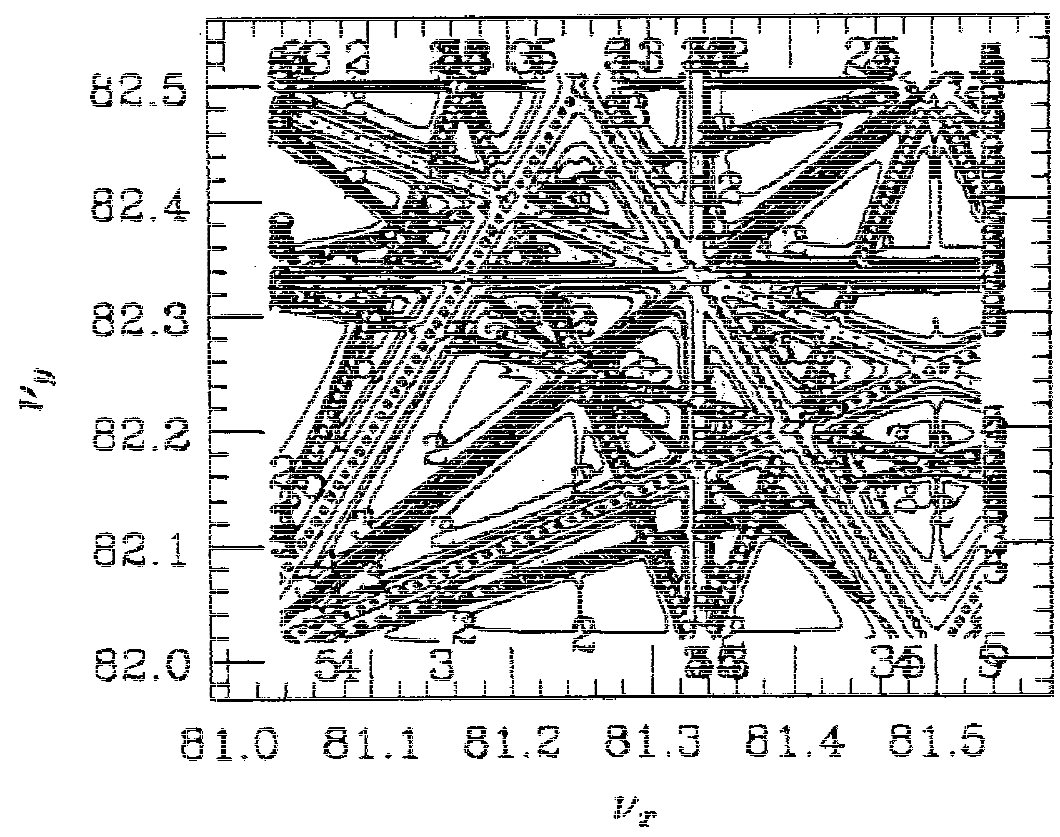

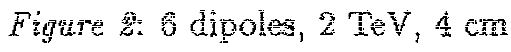




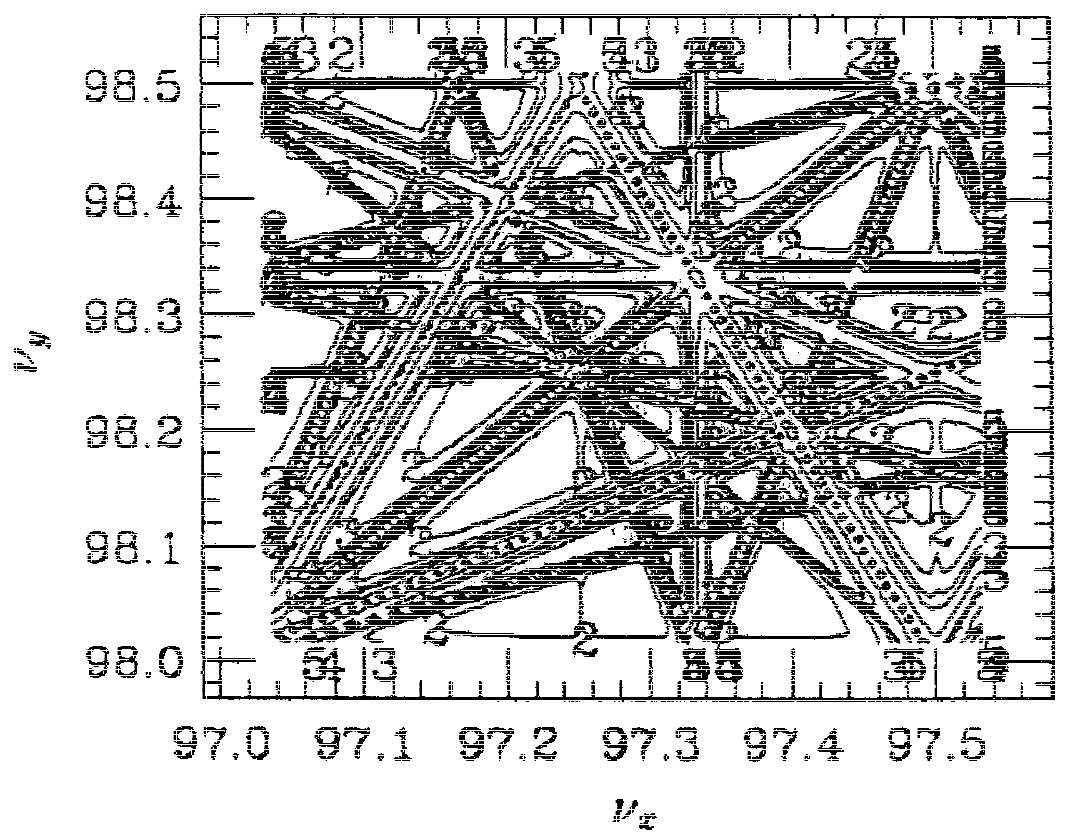

Figure s: 5 dipoles, $1 \mathrm{TeV}, 4 \mathrm{~cm}$

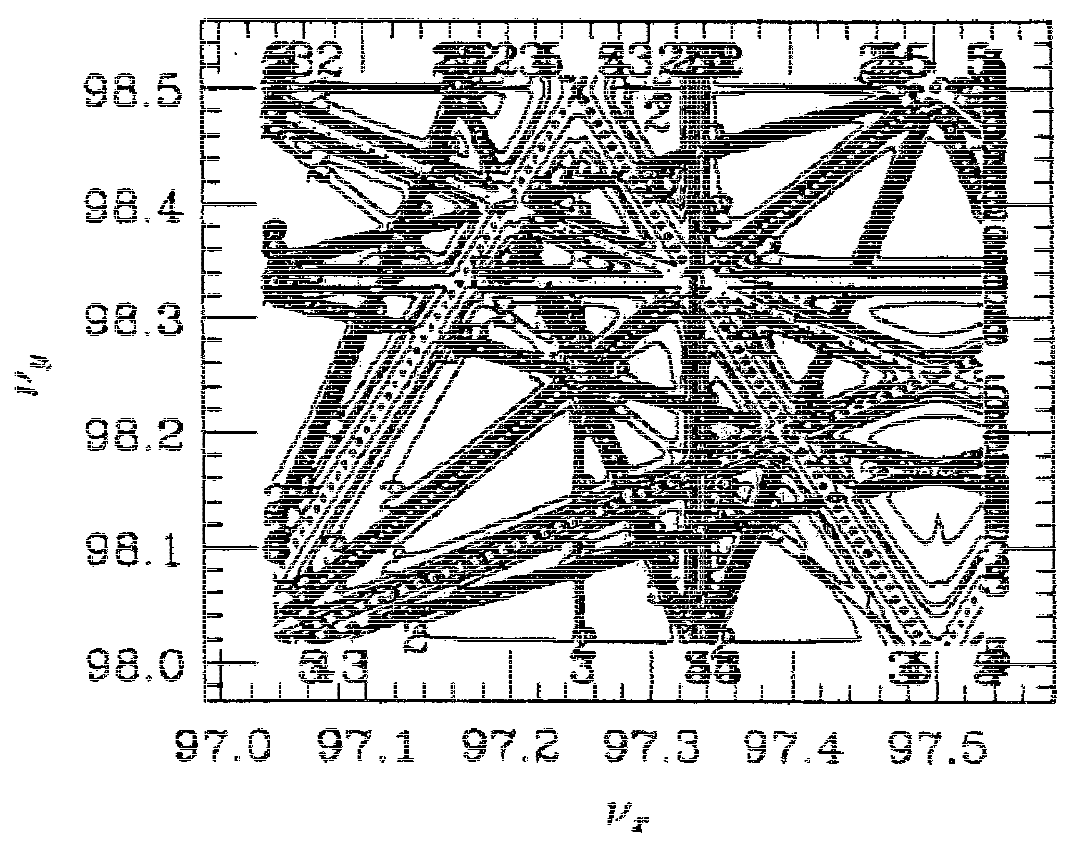

Figure 4: 5 dipoles, $2 \mathrm{TeV}, 4 \mathrm{~cm}$ 


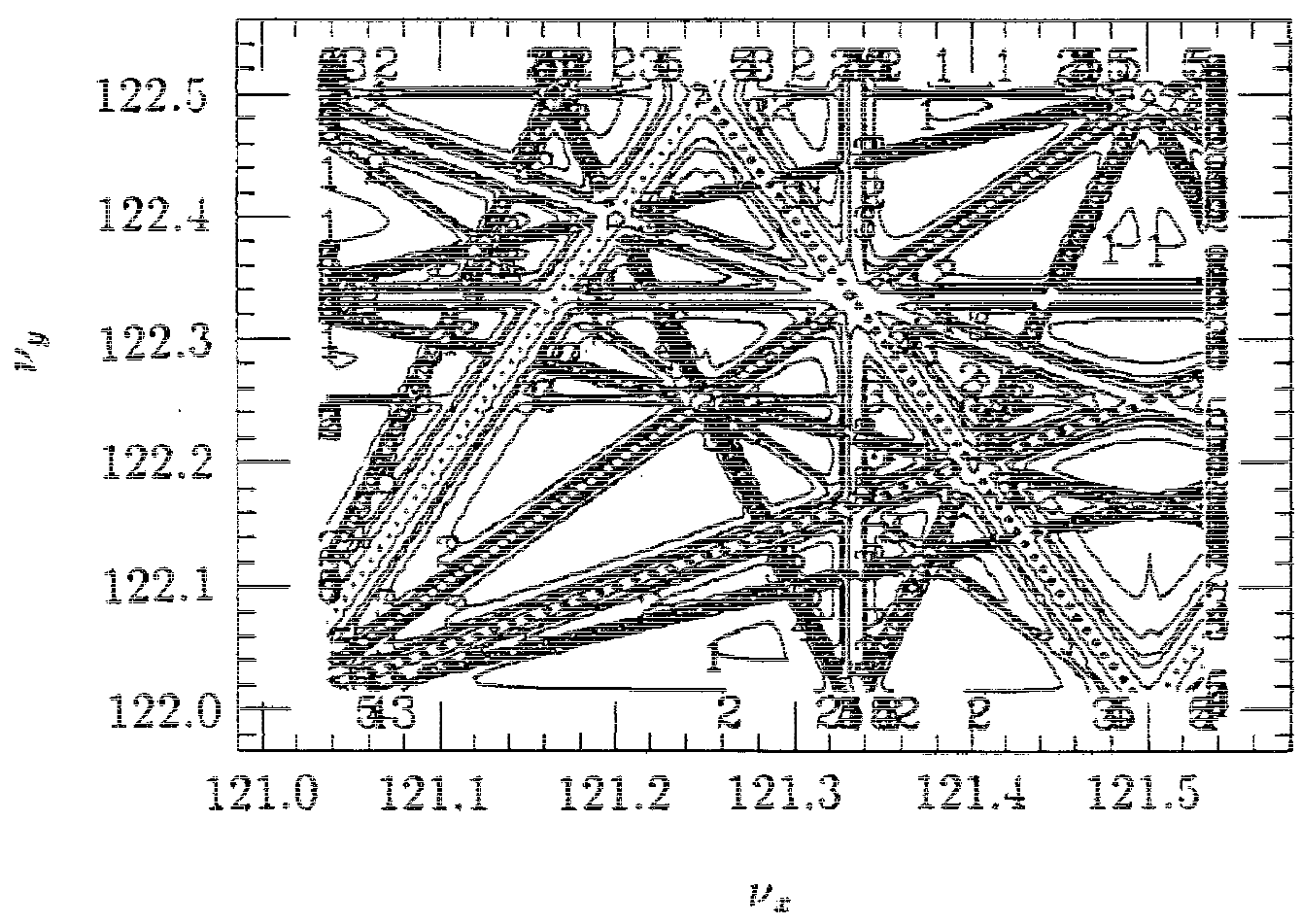

Figare 5: 4 dipoles, $1 \mathrm{TeV}, 4 \mathrm{~cm}$

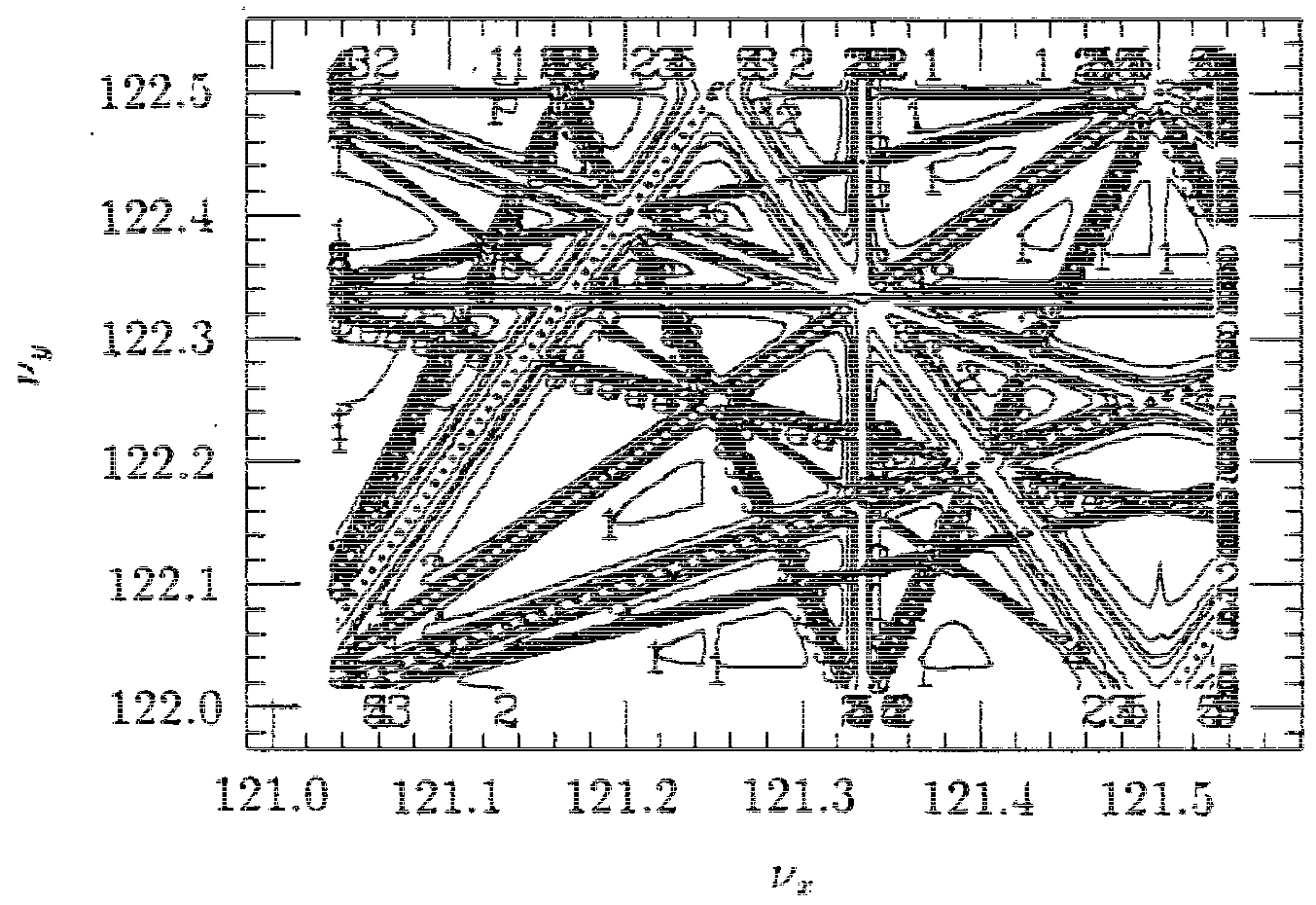

Figure 6: 4 dipoles, $2 \mathrm{TeV} ; 4 \mathrm{~cm}$ 


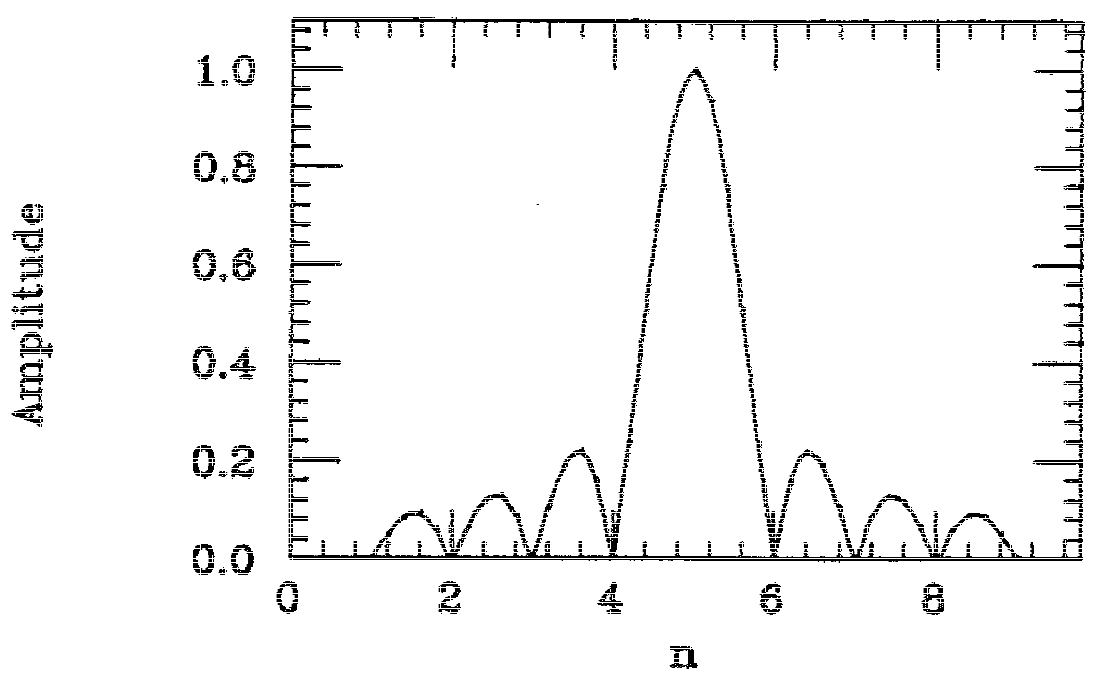

Fâgure 7 Rectangular mindow

shown in Figure 7 . Note that the DFT is only defned for $n=$ integer. From Eq. (8.3) it is possible to derive the following interpolation for the tune. [21]

$$
y=\frac{1}{N}\left[\bar{k}-1+\frac{A(k)}{A(k-1)+A(k)}\right], \quad \bar{k}-1 \leq N_{\nu} \leq k
$$

We have used a sine window to decrease the sidelobes of a peak in the spectrum. This is done by multiplying the samples $x_{k}$ by a weight function, in this case

$$
y_{k}=x_{k} \sin \left(\frac{\pi k}{N}\right), \quad k=0,1,2, \ldots, N-1
$$

leading to the following distribution for a peak

$$
A(k)=\left|\frac{\sin [\pi(k-1 / 2-N \nu)]}{2 \pi(k-1 / 2-N \nu)(k+1 / 2-N \nu)}\right|, \quad k=0,1,2, \ldots, N-1
$$

shown in Figure 8. 


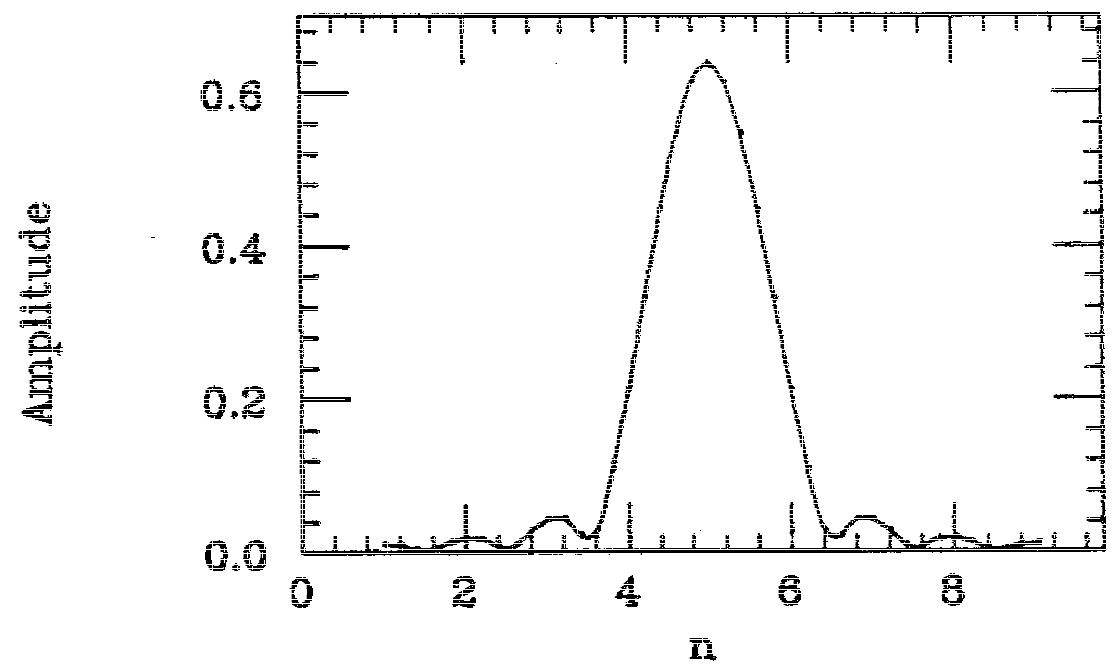

Figure 8 : Sine window

We now have[21]

$$
\nu=\frac{1}{N}\left[k-1+\frac{2 A(k)}{A(k-1)+A(k)}-\frac{1}{2}\right], \quad k=1 \leq N \nu \leq k
$$

When the tune is known, Eq. (8.6) can be used to obtain the amplitude of a peak.

Smear is obtained by calculating the change of the action variable $J$ defined by Eq. (2.9) using the values from the linear lattice calculations as estimates for the alpha and the beta functions. The rms value of $y$ is then estimated from

$$
\sigma_{\bar{J}_{x}}^{* \hat{2}}=\frac{1}{N-1} \sum_{i=1}^{N}\left(\bar{J}_{x}^{*}-J_{x}\right)^{2}
$$


where

$$
\bar{J}_{z}^{*}=\frac{1}{N} \sum_{i=1}^{N} J_{m}
$$

Another possibility is to Fourier analyze $J$. The zeroth hamonic gives the average value of $J$. The average value is then subtracted from the samples, and the ms value of $\Delta J$ is then given by

$$
\sigma_{J_{x}}^{*^{2}}=\sum_{k=0}^{N-1} \frac{A^{2}(k)}{2}
$$

This method has the advantage that the contributions from different mintipoles can be resolved. It is done by noticing that to first order the multipoles $a_{2}, b_{2}, a_{3}$ and $b_{3}$ in the multipole strength only excite different nonlineat amplitude resonances. These can be identified by futing a linear combination of the horizontal and vertical tune to each peak in the spectrum. The contribution to the smear for a given multipole is then obtained by restricting the sum to the relevant peaks. A typical example is shown in Figure 9 .

\subsection{SMEAR DUE TO RANDOM MULTPOLES}

Tracking has been done with randon errors only for a latice with 6 dipoles per half cell and 1 TeV injection energy. [22] The amplitudes were

$$
A_{x}=5.00 \mathrm{~mm}, \quad A_{y}=5.13 \mathrm{~mm}
$$

The smear was obtained as averages over 100 seeds. We therefore expect the agreement to be of the order of

$$
\pm \sigma_{S}= \pm \frac{\sigma_{S}}{\sqrt{100}}
$$

which clearly is the case. The results are shown in Table 16. 

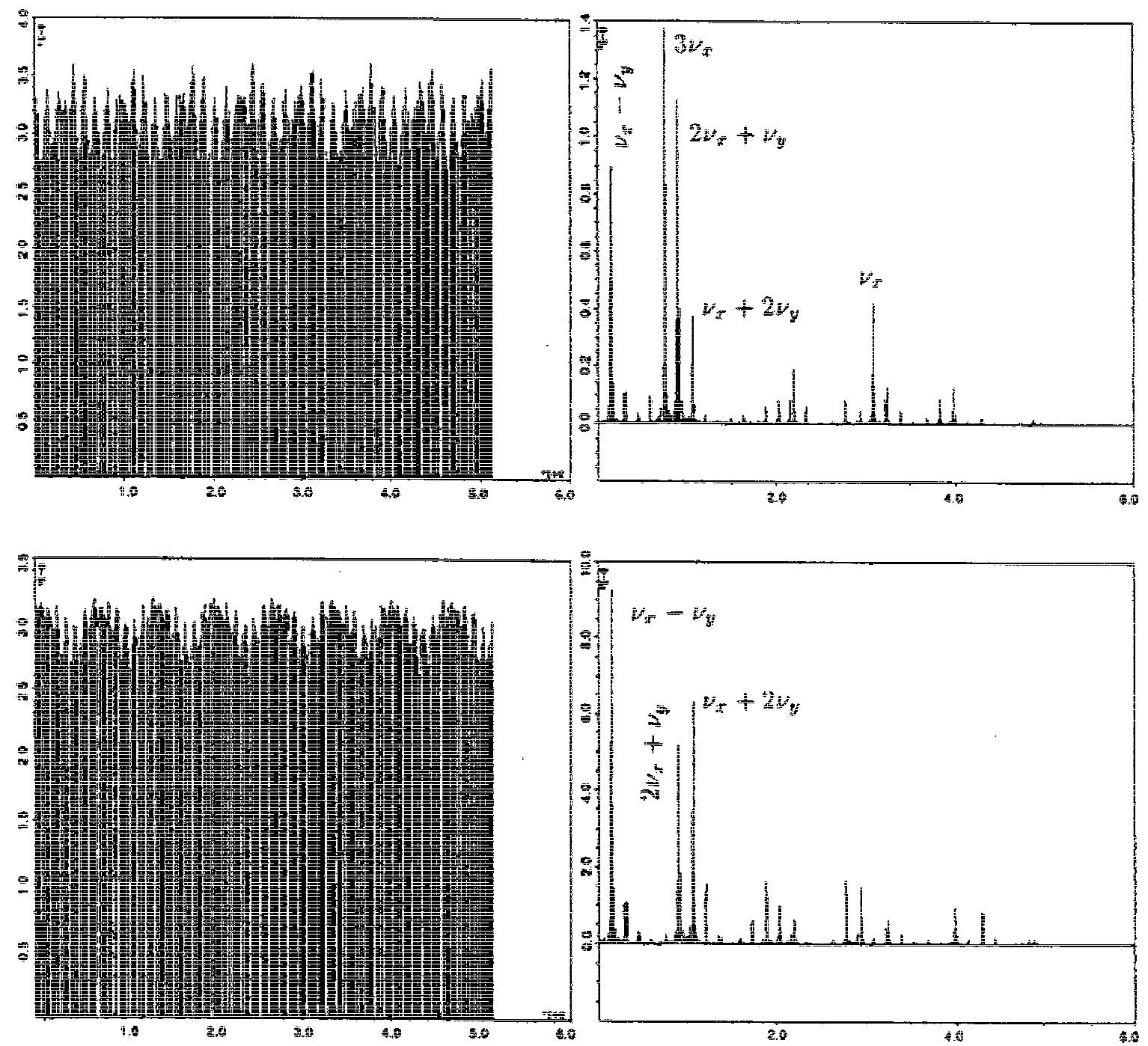

Figure 9: Amplitude resonances

Table 16: Average smear due to random multipoles

\begin{tabular}{ccccc}
\hline \hline$a_{2}$ & $b_{2}$ & $a_{3}$ & $b_{3}$ & total \\
\hline $1.50(1.50 \pm 0.6)$ & $0.87(0.86 \pm 0.3)$ & $3.08(2.96 \pm 1.4)$ & $0.71(0.66 \pm 0.3)$ & $3.62 \pm 1.2(3.49 \pm 1.6)$ \\
$1.11(1.05 \pm 0.4)$ & $0.99(0.90 \pm 0.4)$ & $2.87(2.87 \pm 1.3)$ & $0.75(0.69 \pm 0.3)$ & $3.39 \pm 1.1(3.27 \pm 1.4)$ \\
\hline \hline
\end{tabular}

A histogram for the total horizontal and vertical smear square, due to the definition of Eq. (2.2), obtained from the tracking is shown in Figures 10 and 11. 


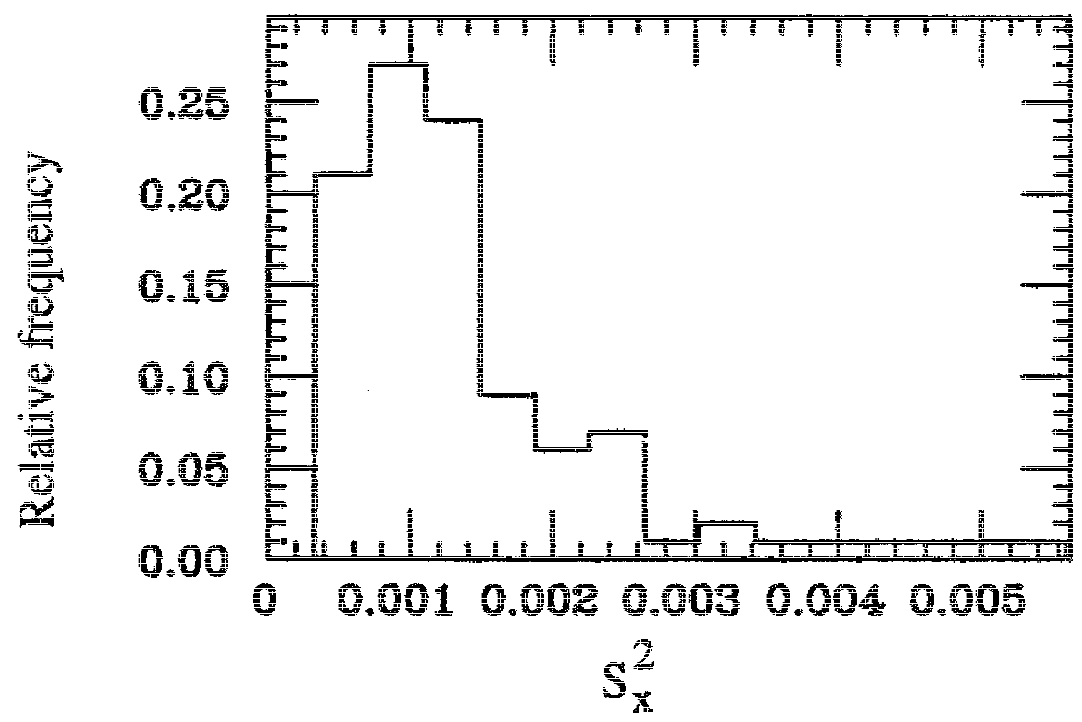

Figne 10: Histogram for the horigontal smear

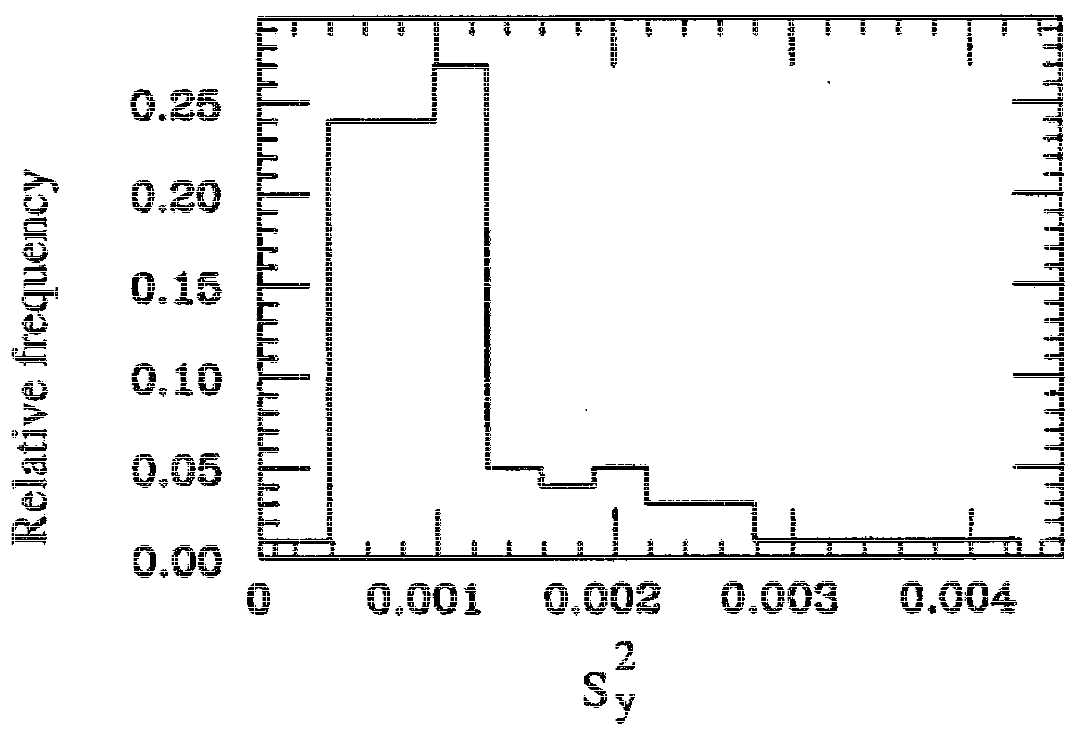

Figure 11: Histogram tor the vertical smear 


\subsection{SMEAR AND TUNE SHITS DUE TO SYSTEMATIO MULTPOLES}

From Table 4-1 in Ref. [23] we have the following results

Table 17

\begin{tabular}{|c|c|c|}
\hline$\underline{A}_{(\mathrm{mm})}=\mathrm{A}_{\mathrm{y}}$ & $b_{2}$ & $\left(\frac{A y}{10^{-3}}\right)$ \\
\hline \multirow[t]{2}{*}{5} & -4.7 & $2.5(2.2)$ \\
\hline & & $2.1(2,0)$ \\
\hline
\end{tabular}

and from page 18 in Ref. [1], we find

Tanle 18:

\begin{tabular}{|c|c|c|}
\hline$\frac{A_{n}}{m}$ & $\underset{(m y)}{A m}$ & $\frac{\Delta \hat{0}^{3}}{\left(10^{-3}\right.}$ \\
\hline \multirow[t]{2}{*}{$\overline{5}$} & 5 & $5.7(5.7)$ \\
\hline & & $5.8(5.3)$ \\
\hline \multirow[t]{3}{*}{5} & 0 & $3.5(3.7)$ \\
\hline & & $2.0(2,0)$ \\
\hline & & $3.7(3.3)$ \\
\hline 0 & 5 & $2.2(2,0)$ \\
\hline
\end{tabular}

for

$$
b_{2}=-7.4, \quad b_{3}=0.1, \quad b_{4}=0.64
$$

and the "SNEUFF" correction scheme. We have checked by tracking with TEAPOT that uncorrected systematic $a_{i}$ and $b_{4}$ give negligible contributions. For the case with 6 dipoles, 1 TeV and 4 cm magnet aperture, we found the contribution to be

$$
\begin{array}{ll}
S_{x}=0.01 \%, & \Delta y_{x}=0.01 \cdot 10^{-3} \\
S_{y}=0.01 \%, & \Delta y_{y}=0.01 \cdot 10^{-3} .
\end{array}
$$


In addition, we found that the second order contribution from uncorrected systematic $b_{2}$ to the smear are

$$
b_{2}=-8.4 ; \quad S_{x}=0.12 \%, \quad S_{y}=0.12 \%
$$

for an anplitude of

$$
A_{\mathrm{x}}=A_{\mathrm{y}}=5.0 \mathrm{~mm}
$$

This is quite negligible. However, since this contribution is octupole-like, it will interfere with the contribution from systematic $b_{3}$. This explains the discrepancy for the uncorrected systematic $b_{3}$ contributions in Table 19. Tracking has also been done for some of the cases in Table 1. The results are shown in Tables 19 and 20.

Tâble 19: 6 dipoles, 1 TeV, 4 cm magnet aperture

\begin{tabular}{lccccc}
\hline \hline \multicolumn{1}{c}{ smear $(\%)$} & $a_{2}$ & $b_{2}$ & $a_{3}$ & $b_{3}$ & total \\
\hline due to systematic mulipoles & $0.05(0.02)$ & $1.04(1.05)$ & $0.09(0.08)$ & $0.12(0.19)$ & $1.05(1.07)$ \\
& $0.02(0.02)$ & $0.50(0.51)$ & $0.06(0.06)$ & $0.11(0.18)$ & $0.52(0.55)$ \\
due to corrected & $0.01(0.01)$ & $0.50(0.51)$ & $0.02(0.01)$ & $0.02(0.00)$ & $0.50(0.51)$ \\
systematic multipoles & $0.00(0.00)$ & $0.26(0.27)$ & $0.01(0.01)$ & $0.02(0.00)$ & $0.20(0.27)$ \\
\hline \multicolumn{1}{c}{$\Delta \nu\left(10^{-3}\right)$} & & & & & total \\
\hline due to systematic multipoles & & & & $20.921 .0)$ \\
& & & & $27.3(28.4)$ \\
due to corrected & & & $6.3(6.5)$ \\
systematic multipoles & & & & $6.4(6.1)$ \\
\hline \hline
\end{tabular}


Table ôt 4 dipoles, $1 \mathrm{TeV}, 4$ cm magnet aperture

\begin{tabular}{lccccc}
\hline \hline \multicolumn{1}{c}{ smear (\%) } & $a_{2}$ & $b_{2}$ & $a_{3}$ & $b_{3}$ & total \\
\hline due to conrected & $0.00(0.00)$ & $0.30(0.30)$ & $0.01(0.01)$ & $0.02(0.00)$ & $0.30(0.30)$ \\
systematic multipoles & $0.00(0.00)$ & $0.26(0.26)$ & $0.01(0.01)$ & $0.01(0.00)$ & $0.26(0.26)$ \\
\hline \multicolumn{1}{c}{$\Delta \nu\left(10^{-3}\right)$} & & & & & total \\
\hline due to conrected & & & & $1.9(1.8)$ \\
systematic multipoles & & & & $1.7(1.5)$ \\
\hline \hline
\end{tabular}

\subsection{CLOSED ORBT DISTORTIONS}

The analyticaly calculated mins orbit has been compared with values obtained from TEAPOT data. [24] Since the corrected orbit is uncorrelated between different cells, the rms orbit was obtained by averaging over the 320 cells of a particular lattice. We have studied the case with one corrector and one bpm per cell for each plane with

$$
\Delta x_{\mathrm{rus}}^{\mathrm{rms}}=0.50 \mathrm{~mm}, \quad \Delta x_{\mathrm{ppm}}^{\mathrm{mms}}=0.71 \mathrm{~mm}
$$

The result is shown in Figure 12 where a dotted line represents the analyticaly calculated horizontal orbit, a dash represents the corresponding TEAPOT data, a dotdash represents the analyical vertical orbit, and a sold represents the conresponding TEAPOT data. The agreenent is quite good, except for a small systematic error in the vertical plane. It is not clear why this error appears. One would expect the two planes to be symmetric as the analytical calculation indicates. In any case, this discrepancy is negligible for the smear calculations.

Since the actial correction schene for the SSC uses two bpm's per cell $[25]$ we have compared the analytical calculations, which are based on one bpm with this case, using

$$
\Delta x_{\mathrm{quad}}^{\mathrm{rms}}=1.00 \mathrm{~mm}, \quad \Delta x_{\mathrm{bpm}}^{\mathrm{rms}}=1.41 \mathrm{~mm}
$$


As can be seen from Figure 13 , it does not lead to any significant change. This is explained by the fact that the corrected orbit is dominated by the bpm errors, and the best that can be achieved is to make the corrected orbit pass through the center of the bpmins.

The analytical results in Table 3 b were compared with tracking using five different seeds in the case of no correction [24]

$$
S_{x}=3.9(4.0), \quad S_{y}=3.8(3.8)
$$

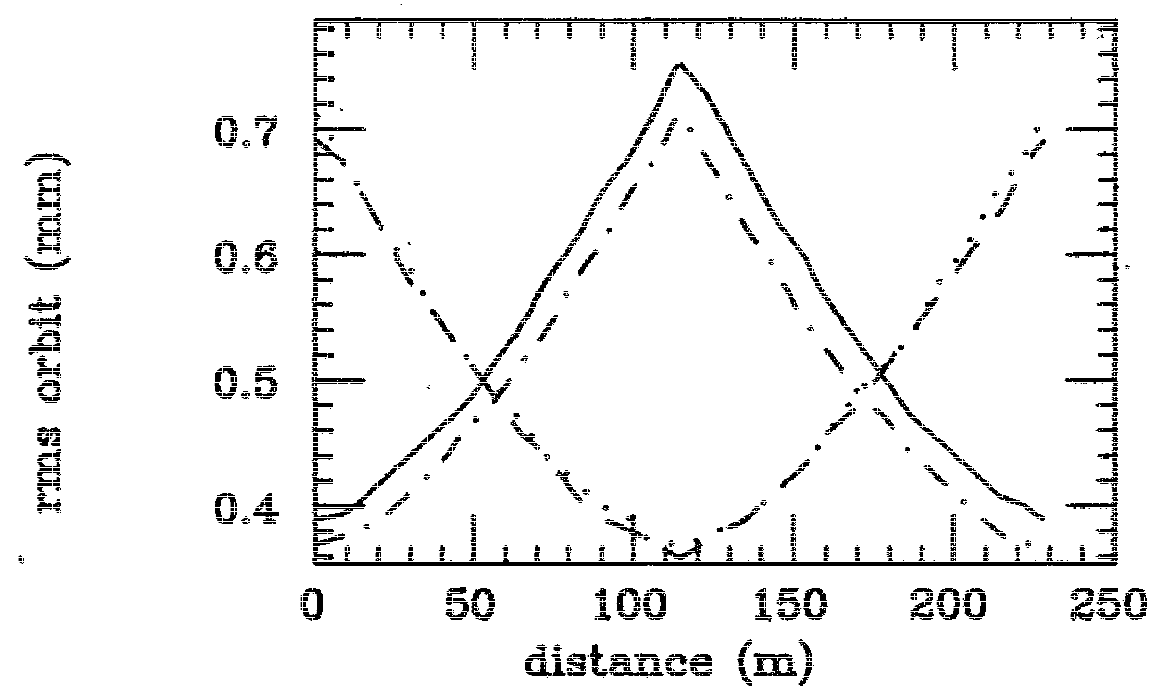

Figure 12: Closed orbit distortions 


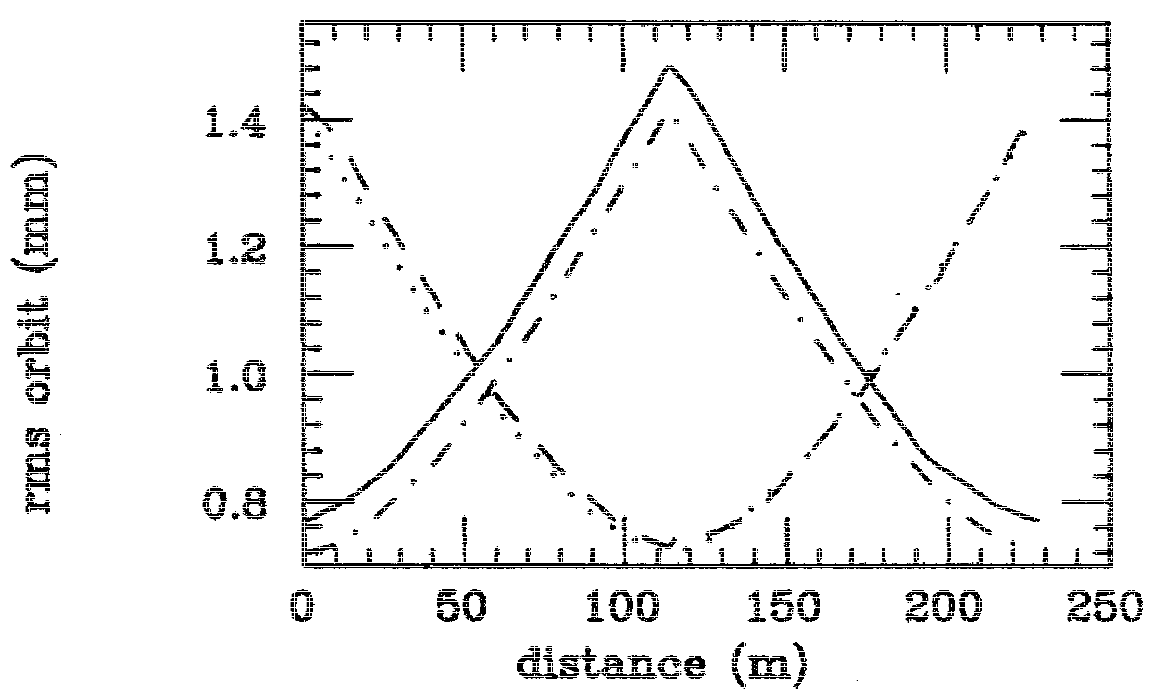

Figure is: Closed orbit distortions

\section{Summary and Conclusions}

We have applied and generalized the Lie algebraic formalism developed by E. Forest to calculate smear and tune shifts due to random and systematic multipole errors for the SSC.

It is clear that the presented analytical expressions for the average smear, the spread of the smear, and the tune shifts reproduce in detail the tracking results. By using analytical techniques, the computation times are reduced from hours on the CRAY to seconds on the VAX. Contributions of various multipoles and closed onbit distortions and dependence on amplitude, momentum, and working point are also clear.

The spread of the smear, typically $40 \%$, should be considered so that a specifed set of parameters will yield the desired linearity.

This study has been limited to the on-momentum case. To be complete, the off momentum contributions have to be included. 


\section{ACKNOWLEDGEMENTS}

We would like to thank $A$. Chao for his support and overall guidance during this work. We would also like to thank the following people for many helpful discussions and suggestions: E. Forest and J. M. Peterson. Finaliy, we would like to thank S. Dutt for comments on how to improve the manuscript and V. Kelly for her assistance during the typing of this document. 


\section{REFERENCES}

1. Correction Element Working Group, Compensation of SSC Lattice Optics in the Presence of Dipole Field Errors, SSC-SR-1038.

2. E. Forest and J. M. Peterson, Correction of Random Muthole Frrors with Iumped Correctors, SSC-N-383.

3. M. A. Fumman and S. G. Peggs, A Standard for the Smear, SSC-N-634.

at. E. Forest, Analytical Computation of the Smear, SSC-95.

5. I. Bengtsson, Nonlinear Transwerse Dymamics for Storage Rings with Applications to the Low Energy Anth-Froton Ring (LEAR) at CERN, CERN 88.05 .

6. K. Y. Ng and N. Merminga, Analytic Expressions for the Smear due to Nonlinear Multipoles, SSC-N-594.

$7 . \mathrm{E}$. D. Courant and H. S. Snyder, The Theory of the Alternating-Gradient Symchrotron, Annals of Physics, 3 (1958) 1.

8. E. Forest, Computation of First Order Tune Shits, SSC-N-322.

9. A. Jackson, Tune Shith and Compensation from Systematic Field Components, SSC-107.

10. SSC Central Design Group, Conceptual Design Report, SSC-SR-2020.

11. Parameters Working Group Report, Magnetic Errors in the SSC, SSC-7.

12. A. A. Garren and D. E. Johnson, The 00-Degree (September 1987) SSC Lattice, $\mathrm{SSC}-146$.

13. A. Dragt, Lectures on Nonbriber Orbit Dunamics, Am. Inst. Phys. Conf. Proc. No. 87, R.A. Carrigan et al. (eds.), New York: AIP(1982) 147.

14. E. Forest, Hamitonian-Free Pertirbation Theory: The Concept of Plase Advance, SSC-111.

15. MACSYMA Reference Manual, Symbolics Inc. (1983). 
16. J. P. Delahaye and J. J. Jager, Voriation of the Dispersion Function, $M$ omentum Compaction Factor, and Damping Partition Numbers with Farticle Energy Deviation, Part. Accel. 18 (1986) 183.

17. E. Forest and J. M. Peterson, private communication.

18. J. Peterson, private communicabion.

19. L. Schachinger, $\mathrm{T}$. Sun, and $\mathrm{R}$. Talman, Manual for the Program TEAPOT; Noninteractive Version, unpublished.

20. J. Clement, TOPDRAWER, Bonner Lab version, Bonner Lab, Rice University, Houston, Texas.

21. E. Asseo, Moyens de Calcul pour la Mesure des Force et Phase des Effets Pertubateurs des Résonances sur le Fascean CERN/PS/LEA Note 87-1 (1987).

22. T. Sun, private communication.

23. D. Neufer and P. Talman, Comparison of Numerical and Analytical Results for the Systematic Tune Variation of Various Lumped Compensation Schemes for the SSC, SSC-N-492.

24. L. Schachinger, private communication.

25. A. W. Chao and S. G. Peggs, Ortist Correction in the Long Ares of the SSO, SSC- 48 . 
